NBER WORKING PAPER SERIES

INEQUALITY IN HUMAN CAPITAL AND ENDOGENOUS CREDIT CONSTRAINTS

Rong Hai

James J. Heckman

Working Paper 22999

http://www.nber.org/papers/w22999

\author{
NATIONAL BUREAU OF ECONOMIC RESEARCH \\ 1050 Massachusetts Avenue \\ Cambridge, MA 02138 \\ December 2016
}

We thank Dean Corbae, Mariacristina De Nardi, Lance Lochner, Steve Stern, and participants at the Human Capital and Inequality Conference held at Chicago on December 17th, 2015, for helpful comments and suggestions on an earlier draft of this paper. We also thank Joseph Altonji, Peter Arcidiacono, Panle Jia Barwick, Jeremy Fox, Jorge García, Limor Golan, Lars Hansen, John Kennan, Rasmus Lentz, Maurizio Mazzocco, Aloysius Siow, Ronni Pavan, John Rust, Bertel Schjerning, Christopher Taber, and participants at the Cowles Conference in Structural Microeconomics and the Stanford Institute for Theoretical Economics (SITE) Summer Workshop for helpful comments. We also thank two anonymous referees. Yu Kyung Koh provided very helpful comments on this paper. This research was supported in part by: the Pritzker Children's Initiative; the Buffett Early Childhood Fund; NIH grants NICHD R37HD065072, NICHD R01HD054702, and NIA R24AG048081; an anonymous funder; Successful Pathways from School to Work, an initiative of the University of Chicago's Committee on Education and funded by the Hymen Milgrom Supporting Organization; the Human Capital and Economic Opportunity Global Working Group, an initiative of the Center for the Economics of Human Development and funded by the Institute for New Economic Thinking; and the American Bar Foundation. The views expressed in this paper are solely those of the authors and do not necessarily represent those of the funders or the official views of the National Institutes of Health. The views expressed herein are those of the authors and do not necessarily reflect the views of the National Bureau of Economic Research.

NBER working papers are circulated for discussion and comment purposes. They have not been peer-reviewed or been subject to the review by the NBER Board of Directors that accompanies official NBER publications.

(C) 2016 by Rong Hai and James J. Heckman. All rights reserved. Short sections of text, not to exceed two paragraphs, may be quoted without explicit permission provided that full credit, including $(\odot$ notice, is given to the source. 
Inequality in Human Capital and Endogenous Credit Constraints

Rong Hai and James J. Heckman

NBER Working Paper No. 22999

December 2016

JEL No. I2,J2

\begin{abstract}
$\underline{\text { ABSTRACT }}$
This paper investigates the determinants of inequality in human capital with an emphasis on the role of the credit constraints. We develop and estimate a model in which individuals face uninsured human capital risks and invest in education, acquire work experience, accumulate assets and smooth consumption. Agents can borrow from the private lending market and from government student loan programs. The private market credit limit is explicitly derived by extending the natural borrowing limit of Aiyagari (1994) to incorporate endogenous labor supply, human capital accumulation, psychic costs of working, and age. We quantify the effects of cognitive ability, noncognitive ability, parental education, and parental wealth on educational attainment, wages, and consumption. We conduct counterfactual experiments with respect to tuition subsidies and enhanced student loan limits and evaluate their effects on educational attainment and inequality. We compare the performance of our model with an influential ad hoc model in the literature with education-specific fixed loan limits. We find evidence of substantial life cycle credit constraints that affect human capital accumulation and inequality. The constrained fall into two groups: those who are permanently poor over their lifetimes and a group of well-endowed individuals with rising high levels of acquired skills who are constrained early in their life cycles. Equalizing cognitive and noncognitive ability has dramatic effects on inequality. Equalizing parental backgrounds has much weaker effects. Tuition costs have weak effects on inequality.
\end{abstract}

\author{
Rong Hai \\ Department of Economics \\ University of Miami \\ 314P Jenkins \\ Coral Gables, FL 33146 \\ rhai@bus.miami.edu \\ James J. Heckman \\ Department of Economics \\ The University of Chicago \\ 1126 E. 59th Street \\ Chicago, IL 60637 \\ and IZA \\ and also NBER \\ jjh@uchicago.edu
}

A data appendix is available at http://www.nber.org/data-appendix/w22999 


\title{
Inequality in Human Capital and Endogenous Credit Constraints
}

\author{
Rong Hai ${ }^{\mathrm{a}, *}$, James J. Heckman ${ }^{\mathrm{b}}$ \\ ${ }^{a}$ Department of Economics, University of Miami, 314P Jenkins Building, Coral Gables, FL, 33146, USA \\ ${ }^{b}$ Department of Economics, University of Chicago, 1126 East 59th Street, Chicago, IL 60637, USA; phone: \\ 773-702-0634; fax: 773-702-8490
}

\begin{abstract}
This paper investigates the determinants of inequality in human capital with an emphasis on the role of the credit constraints. We develop and estimate a model in which individuals face uninsured human capital risks and invest in education, acquire work experience, accumulate assets and smooth consumption. Agents can borrow from the private lending market and from government student loan programs. The private market credit limit is explicitly derived by extending the natural borrowing limit of Aiyagari (1994) to incorporate endogenous labor supply, human capital accumulation, psychic costs of working, and age. We quantify the effects of cognitive ability, noncognitive ability, parental education, and parental wealth on educational attainment, wages, and consumption. We conduct counterfactual experiments with respect to tuition subsidies and enhanced student loan limits and evaluate their effects on educational attainment and inequality. We compare the performance of our model with an influential ad hoc model in the literature with education-specific fixed loan limits. We find evidence of substantial life cycle credit constraints that affect human capital accumulation and inequality. The constrained fall into two groups: those who are permanently poor over their lifetimes and a group of well-endowed individuals with rising high levels of acquired skills who are constrained early in their life cycles. Equalizing cognitive and noncognitive ability has dramatic effects on inequality. Equalizing parental backgrounds has much weaker effects. Tuition costs have weak effects on inequality.
\end{abstract}

Keywords: Human Capital, Credit Constraints, Natural Borrowing Limit, Education, Wealth JEL codes: I2, J2

\section{Introduction}

This paper develops and estimates a dynamic model of schooling and work experience in which agents are subject to uninsured human capital risks and face restrictions on their borrowing possibilities. We analyze unsecured borrowing limits with endogenous labor supply and human capital accumulation. We estimate the structural parameters of preferences and

\footnotetext{
${ }^{*}$ Corresponding author

Email addresses: rhai@bus.miami.edu (Rong Hai), jjh@uchicago.edu (James J. Heckman)
} 
the technology of human capital production. They completely characterize the borrowing limits for heterogeneous agents. Accounting for borrowing limits in an environment with no asymmetries in information between lenders and borrowers where agents make consumption, human capital, and labor supply decisions has important consequences for understanding educational choices and human capital investment.

There is a growing body of evidence supporting the empirical importance of credit constraints in affecting educational attainment. As noted in Lochner and Monge-Naranjo (2015), the early literature found little evidence for them. The recent literature - based on more recent data - shows much stronger evidence for credit constraints, a phenomenon first noted in Belley and Lochner (2007), and documented in later studies (Bailey and Dynarski, 2011, Lochner and Monge-Naranjo, 2012, and Johnson, 2013).

Previous empirical research on this topic fixes lending limits at ad hoc values, or else introduces additional "free parameters" to model credit limits. In our analysis, agents can borrow up to model-determined limits derived from an analysis of private lending with a natural limit combined with access to government student loan programs. No ad hoc or free parameters are introduced.

Ours is the first analysis that extends the natural borrowing limit of Aiyagari to simultaneously encompass endogenous labor supply, consumption, human capital accumulation, and savings in physical capital. Our model predicts that borrowing limits are lower for individuals who have lower levels of human capital and higher psychic costs of working. The predicted credit limits vary with age, first increasing, and then decreasing. Following Aiyagari (1994), we assume that lenders can fully enforce contracts and collect on resources available to individuals. Borrowers must repay as long as they have resources. However, different from Aiyagari (1994), agents in our model have the option of not working. Lenders cannot force borrowers to work and human capital productivity shocks are uninsurable. The lending/enforcement protocol is that lenders can enforce full repayment subject to the restriction that borrowers must be provided a minimum consumption level that satisfies individual 
rationality constraints for working.

We use our estimated model to analyze the cross-sectional characteristics and the age profiles of the borrowing constrained population. We find that credit-constrained agents fall roughly into two groups: (a) those with poor initial endowments and family background who acquire little human capital, have low wage levels, and little life cycle wage growth, and (b) those who are able and from good family backgrounds who have more education, less work experience, high wage levels, and substantial life cycle wage growth. The first group of agents is constrained throughout their life cycles. The second group is constrained in their late 20s and early 30s, although they have high levels of life cycle wealth and human capital and rapid wage growth. They cannot fully smooth consumption in the early stages of their life cycles.

There is a corresponding two-humped profile of constrained agents with respect to endowments and abilities at the early stages of labor market entry. As income is harvested over the life cycle, the second hump (associated with the second, more affluent group) disappears. The first group with poor initial conditions remains constrained over its lifetime. This group of individuals has low labor market earnings, little savings, and small borrowing limits. Persons in this group have high discount rates and thus are less patient. They want consumption upfront but cannot access it due to their low borrowing limits.

Our paper extends the existing literature in other dimensions by analyzing how cognitive and noncognitive ability affects choices through (i) psychic costs of working and schooling; (ii) the technology of human capital production; and (iii) discount factors. Following Cunha and Heckman (2008) and Cunha et al. (2010), we allow our measures of abilities to be fallible. We introduce heterogeneity in parental transfers which is not investigated in the existing literature.

We use our estimated model to understand the sources of inequality in education, wages, and consumption over the life cycle. We consider how parental characteristics and transfers, as well as credit markets, affect choices and outcomes. We find strong effects of adolescent 
endowments of cognitive and noncognitive ability on human capital development. Tuition costs and family transfers to children also play important roles in explaining differences in human capital investments.

We conduct counterfactual policy experiments using our estimated model. We examine the impact of equalizing initial endowments on inequality in consumption, wages, and human capital. We also examine the consequences of reducing tuition and increasing student loan limits on college attendance and graduation.

We compare our model with a recent model in the literature that fixes loan limits by education level in an ad hoc fashion (Abbott et al., 2016). Using their specification, estimated subjective discount rates are smaller than in our model with endogenous credit limits. The goodness of fit is somewhat worse. Comparing counterfactual outcomes, the model with fixed credit limits by education predicts a higher elasticity of educational response to tuition than our model with the fully endogenous borrowing limit. The ad hoc model also predicts a much larger effect of increasing student loans on college enrollment and 4-year college completion.

The rest of the paper is organized as follows. Section 2 gives a brief overview of the literature on human capital accumulation and credit constraints and places our paper in the context of this literature. Section 3 presents our model. Section 4 describes the data and conducts basic regression analyses that summarize the empirical regularities in the data. Section 5 presents our empirical strategy for estimating the model. Section 6 discusses our estimates. Section 7 conducts counterfactual simulations. Section 8 compares estimates of our model with estimates from an ad hoc model of credit constraints. Section 9 concludes.

\section{This Paper in Context: A Brief Review of the Literature on the Specification of Credit Constraints}

This paper contributes to the literature on schooling and credit constraints (see Lochner and Monge-Naranjo, 2012, 2015 and Heckman and Mosso, 2014 for overviews). The evidence of the importance of credit constraints and their effect on schooling decisions has evolved. 
Cameron and Taber (2004) reject the null hypothesis of binding credit constraints in NLSY79 data. Using NLSY79 and NLSY79 Children (CNLSY79), Carneiro and Heckman (2002) find that the role of family income in determining college enrollment decisions is very small once ability is accounted for. Linking information between children and parents (CNLSY79 and NSLY79), Caucutt and Lochner (2012) find strong evidence of credit constraints among young and highly educated parents with steeply rising wage profiles.

Table 1 presents a concise overview of the structural literature on credit constraints and schooling. Using the National Longitudinal Survey of Youth 1979 (NLSY79) data, Keane and Wolpin (2001) estimate a structural life cycle model and show that borrowing constraints exist. However, they have no quantitative impact on schooling decisions. ${ }^{1}$ More recent studies suggest that borrowing constraints play a substantial role in college enrollment decisions in the National Longitudinal Survey of Youth 1997 (NLSY97) cohorts (see Belley and Lochner, 2007, Bailey and Dynarski, 2011, and Lochner and Monge-Naranjo, 2012).

Abbott et al. (2016) compare partial and general equilibrium effects of alternative financial aid policies intended to promote college participation in an overlapping generations framework. They impose ad hoc education-specific borrowing limits. They find evidence that student loan programs affect schooling. They report that in the presence of their assumed credit market imperfections, the current configuration of federal loans and grant programs has substantial value in terms of both output and welfare, but further expansions of these programs would only marginally improve aggregate outcomes. Blundell et al. (2016) estimate a dynamic model of employment, educational choices, and savings for women in the UK, assuming an exogenous borrowing limit that is either zero or the amount of the student loan borrowed. They do not discuss the empirical consequences of relaxing this constraint.

\footnotetext{
${ }^{1}$ Keane and Wolpin (2001) assume parental transfers to be a function of parents' schooling, the current school attendance status of the youth, and a number of the youth's assets. However, they do not actually observe parental transfers in their data.
} 


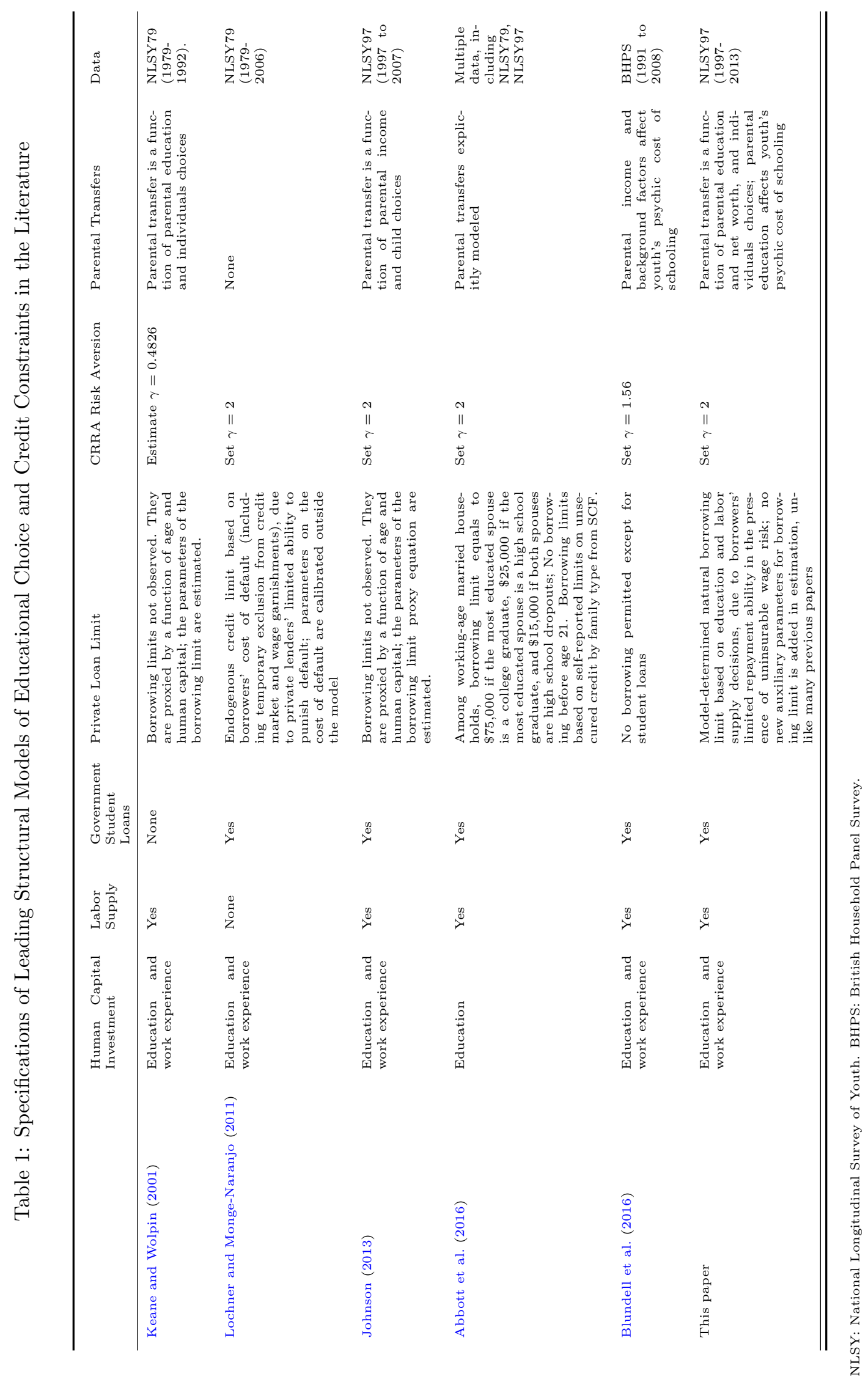




\section{Model: Specification, Solution Concepts, Initial Conditions, and Measure- ment System}

This section presents our model specification, solution concepts, treatment of initial conditions, and associated measurement system. We start by specifying our model.

\subsection{Choice Set}

At each age $t \in\left\{t_{0}, \ldots, T\right\}$ an individual makes decisions under uncertainty about: (i) consumption $c_{t}$ and savings $s_{t+1}$, (ii) whether to go to school $d_{e, t} \in\{0,1\}$, and (iii) employment $d_{k, t} \in\{0,0.5,1\}$, where $d_{k, t}=0, d_{k, t}=0.5$ and $d_{k, t}=1$ indicate not working, working part-time, and working full-time, respectively. ${ }^{2}$ An individual cannot go to school and work full-time at the same time, i.e. $d_{e, t}+d_{k, t}<2$. However, individuals can work parttime while in school. Let $h\left(d_{k, t}\right)$ denote the annual hours of work associated with employment choices $d_{k, t}$. Thus, $h(0)=0<h(0.5)<h(1)$. The cost of schooling includes monetary costs (tuition and fees), psychic costs, and foregone earnings.

\subsection{State Variables and Information Set}

At each age $t$, an individual is characterized by a vector of predetermined state variables that shape preferences, production technology, and outcomes:

$$
\bar{\Omega}_{t}:=\left(t, \boldsymbol{\theta}, e_{t}, k_{t}, s_{t}, d_{e, t-1}, e_{p}, s_{p}\right)
$$

where $\boldsymbol{\theta}$ is a vector that summarizes individual components of unobserved (by the economist) heterogeneity (unobserved cognitive ability and noncognitive ability), $e_{t}$ is the individual's years of schooling at $t, k_{t}$ is accumulated years of work experience at $t, s_{t}$ is net worth determined at the end of period $t-1, d_{e, t-1}$ is the schooling status in the previous period, $e_{p}$ is parental educational level, and $s_{p}$ is parental net worth. ${ }^{3}$

\footnotetext{
${ }^{2}$ In the data, majority of the population completed their educational choices before age 27 , thus we assume the schooling choice $d_{e, t}=1$ is not available after age 27 .

${ }^{3}$ Individuals' unobserved heterogeneity $\boldsymbol{\theta}$ and parental education and wealth $\left(e_{p}, s_{p}\right)$ are measured at the initial period in our model, which is age 17 .
} 
There are three sources of uncertainty in the model: productivity shocks to human capital $\epsilon_{w, t}$, preference shocks to schooling $\epsilon_{e, t}$, and shocks to parental transfers $\epsilon_{p, t}$. (They are introduced below in the context of the specific equations where they appear.) The information set includes all of the predetermined state variables and realized idiosyncratic (serially uncorrelated) shocks at age $t, \epsilon_{t}:=\left(\epsilon_{e, t}, \epsilon_{w, t}, \epsilon_{p, t}\right)$. It can be written as $\boldsymbol{\Omega}_{t}:=$ $\left\{\overline{\boldsymbol{\Omega}}_{t}, \boldsymbol{\epsilon}_{t}\right\}$.

\subsection{Preferences}

An individual has well-defined preferences over consumption $c_{t}$ and choices on schooling and working $\left(d_{e, t}, d_{k, t}\right)$ :

$$
U\left(c_{t}, d_{e, t}, d_{k, t} ; \boldsymbol{\Omega}_{t}\right)=u_{c}\left(c_{t} ; \boldsymbol{\Omega}_{t}\right)+u_{e}\left(\boldsymbol{\Omega}_{t}\right) \cdot d_{e, t}+u_{k}\left(d_{k, t}, d_{e, t}, \boldsymbol{\Omega}_{t}\right) .
$$

The function $u_{c}\left(c_{t} ; \boldsymbol{\Omega}_{t}\right)$ describes utility over consumption. The function $u_{e}\left(\boldsymbol{\Omega}_{t}\right)$ characterizes the psychic costs and the preference shock associated with schooling $\left(d_{e, t}=1\right)$. $u_{k}\left(d_{k, t}, d_{e, t}, \boldsymbol{\Omega}_{t}\right)$ captures the psychic benefits/costs associated with the labor supply decision $d_{k, t} \in\{0,0.5,1\}$. We allow the psychic benefits/costs of part-time working to be different depending on whether the agent is enrolled in school $d_{e, t} \in\{0,1\}$. Agents discount future returns using a subjective discount factor $\exp (-\rho(\boldsymbol{\theta}))$, where $\rho(\boldsymbol{\theta})>0$ is the subjective discount rate that depends on unobserved ability $\boldsymbol{\theta}$.

\subsection{Human Capital Production and Wage Equations}

Human capital at age $t$ (measured in labor efficiency units), $\psi_{t} \in \mathbb{R}^{++}$, is characterized by the following equation:

$$
\psi_{t}=F^{\psi}\left(e_{t}, k_{t}, \boldsymbol{\theta}, \epsilon_{w, t}\right)
$$

where $\epsilon_{w, t} \geq \underline{\epsilon}_{w}$ is an idiosyncratic shock to the human capital stock at age $t$. Equation (3) incorporates two types of human capital: education and work experience, both of which are consequences of investment decisions which we model. Equation (3) allows for productivity in the labor market to depend on cognitive and noncognitive skills $(\boldsymbol{\theta})$. 
An individual's hourly wage offer depends on his human capital, whether he works parttime or full-time, and whether the individual is enrolled in school:

$$
w_{t}=\psi_{t} \cdot F^{w}\left(d_{k, t}, d_{e, t}\right)
$$

where $F^{w}\left(d_{k, t}, d_{e, t}\right)$ is the market price per unit human capital. We allow the rental price of human capital to be different between part-time jobs and full-time jobs. The part-time wage may differ depending on whether the individual is enrolled in school (see Johnson, 2013). We normalize the market price of human capital for a full-time job to be unity (i.e., $\left.F^{w}(1,0)=1\right)$. Thus, an individual's full-time wage offer equals to his human capital level: $w_{t}=\psi_{t}=F^{\psi}\left(e_{t}, k_{t}, \boldsymbol{\theta}, \epsilon_{w, t}\right)$ if $d_{k, t}=1$.

After leaving school, the accumulated years of work experience evolves via:

$$
k_{t+1}=k_{t}+\mathbf{1}\left(d_{k, t}>0\right)-\delta_{k} k_{t} \mathbf{1}\left(d_{k, t}=0\right):=F^{k}\left(k_{t}, d_{k, t}\right)
$$

where $\delta_{k}$ is the depreciation rate of work experience in each period when the individual does not work. Education level at $t+1$, measured by years of schooling, evolves according to the following relationship:

$$
e_{t+1}=e_{t}+d_{e, t}
$$

\subsection{Financial Market Frictions and Endogenous Credit Constraints}

To finance education and consumption, individuals can borrow at a fixed interest rate $r_{b}$. Individuals can also accumulate physical assets at riskless rate $r_{l}{ }^{4}$ To capture an important feature of imperfect capital markets, we allow the lending rate to be smaller than the borrowing rate, i.e., $r_{l}<r_{b}{ }^{5}$

The smallest amount of net worth $s_{t+1}$ that an agent can hold at the end of period $t$

\footnotetext{
${ }^{4}$ We abstract from portfolio choices.

${ }^{5}$ We only need to keep track of an agent's net worth. There is no need to separately keep track of an agent's debts and assets.
} 
is captured by a (potentially negative) lower bound $\underline{S}_{t+1} \in \mathbb{R}^{-}$, which is determined by both the private loan market borrowing limit and the maximum credit from the government student loan programs as follows:

$$
s_{t+1} \geq \underline{S}_{t+1}:=-\max \left\{d_{e, t} \cdot \bar{L}^{g}\left(e_{t}+d_{e, t}\right), \bar{L}_{t}^{s}\left(e_{t+1}, k_{t+1}, \boldsymbol{\theta}\right)\right\}
$$

where $\bar{L}^{g}\left(e_{t}+d_{e, t}\right) \in \mathbb{R}^{+}$is the maximum government student loan credit for schooling level $\left(e_{t}+d_{e, t}\right)$ if the individuals choose to enroll in school $\left(d_{e, t}=1\right)$, and $\bar{L}_{t}^{s}\left(e_{t+1}, k_{t+1}, \boldsymbol{\theta}\right) \in \mathbb{R}^{+}$is the natural borrowing limit of an individual in the private debt market. $\bar{L}_{t}^{s}\left(e_{t+1}, k_{t+1}, \boldsymbol{\theta}\right)$ is determined by the maximum loan that the individual can pay back with probability one at the end of his decision period $T$, i.e., $\bar{L}_{T}^{s}=0$. We discuss the formulation of the endogenous natural borrowing limit $\bar{L}_{t}^{s}(\cdot)$ in Section 3.8 below.

After leaving school, the borrowing limits $\underline{S}_{t+1}$ are enforced in the following ways. ${ }^{6}$ Consider two different situations. First, if an agent's current debt level does not exceed his private debt limit during previous period (i.e., $\left.s_{t} \geq-\bar{L}_{t-1}^{s}\left(e_{t}, k_{t}, \boldsymbol{\theta}\right)\right)$, which could happen if the agent did not borrow more than his private debt limit when in school or the agent (voluntarily) paid down his previous student debt, his lower bound on net worth at the end of period $t$ is given by his private market natural borrowing limit (i.e. $\underline{S}_{t+1}=-\bar{L}_{t}^{s}\left(e_{t+1}, k_{t+1}, \boldsymbol{\theta}\right)$ ). By construction, there will be no default in the model under such a situation.

Second, suppose that an agent's current debt level exceeds his private debt limit during the previous period (i.e., $\left.s_{t}<-\bar{L}_{t-1}^{s}\left(e_{t}, k_{t}, \boldsymbol{\theta}\right)\right)$. This can only happen if the agent borrows from student loan programs. Since he is not forced to repay the debt, we reset the asset lower bound $\underline{S}_{t+1}$ equal to the agent's current debt level (i.e. $\underline{S}_{t+1}=s_{t}<0$ ) for $t \leq T-1$. This is designed to capture the fact that students are not forced to repay their student loans immediately. Student loans, in general, cannot be discharged through bankruptcy. ${ }^{7}$ Therefore, the model assumes that student debt will remain with the borrower until it is

\footnotetext{
${ }^{6}$ See Johnson (2013).

${ }^{7}$ See Lochner and Monge-Naranjo (2015) for evidence supporting this assumption.
} 
repaid. At the end of period $T$, the agent must pay back his student loans up to his available resources. Any remaining unpaid student loans which the agent does not have resources to pay, are forgiven. ${ }^{8}$ While in principle agents can plan to carry student debt through the end of life and then default, doing so reduces their ability to borrow further over the lifetime to smooth consumption. ${ }^{9}$

\subsection{Budget Constraint and Transfer Functions}

To finance a youth's college tuition and fees, parents may provide financial transfers $t r_{p, t} \geq 0$. Parental financial transfers are generated by a stochastic function that depends on (i) parents' wealth terciles $\left(s_{p}\right)$ and parents' education $\left(e_{p}\right)$; (ii) decisions about schooling and employment $\left(d_{e, t}, d_{k, t}\right)$; (iii) youth's cognitive ability and noncognitive ability $(\boldsymbol{\theta})$ and current education $\left(e_{t}\right)$ and age $t$. This is captured by:

$$
t r_{p, t}=t r_{p}\left(e_{p}, s_{p}, d_{e, t}, d_{k, t}, \boldsymbol{\theta}, e_{t}, t, \epsilon_{p, t}\right)
$$

where $\epsilon_{p, t}$ is an idiosyncratic shock to parental transfers. Examples of parental monetary transfers include college financial gifts if the youth chooses to attend college. The parental transfer rule is determined outside our model. It captures paternalism and tied transfers on the part of the parents, which is consistent with the findings of previous research (see, e.g., Keane and Wolpin, 2001 and Johnson, 2013).

Our parental transfer function allows for more heterogeneity in family transfers than those used in Keane and Wolpin (2001) and Johnson (2013). In our parental transfer function specification, even among the students who make the same schooling-working decisions, there is heterogeneity in parental transfers due to differences in (1) parents' net worth and parents' education, which affect total available resources to the youth, (2) the youth's own cognitive

\footnotetext{
${ }^{8}$ In the case of involuntary default at the end of period $T$, the agent will consume a minimum sustainable consumption level $c_{T}=c_{\text {min }}>0$ and $S_{T+1}=0$. We will discuss $c_{\min }$ in the next section (Section 3.6).

${ }^{9}$ Under the estimated model parameter values, our simulation shows that there is no default at the end of last period $T$ among the simulated individuals.
} 
ability and noncognitive ability, which affect the psychic and labor market monetary returns of education, and (3) the shocks to the transfer function $\left(e_{p, t}\right){ }^{10}$

Defining $r\left(s_{t}\right):=r_{l} \mathbf{1}\left(s_{t}>0\right)+r_{b} \mathbf{1}\left(s_{t}<0\right)$, the budget constraint for an individual who chooses to attend college (i.e., $\left.d_{e, t} \cdot \mathbf{1}\left(e_{t}+d_{e, t} \geq 13\right)=1\right)$ is:

$$
\begin{gathered}
c_{t}+\left(t c\left(e_{t}+d_{e, t}\right)-g r\left(e_{t}+d_{e, t}, s_{p}\right)\right)+s_{t+1} \\
=\left(1+r\left(s_{t}\right)\right) \cdot s_{t}+w_{t} \cdot h\left(d_{k, t}\right)+t r_{p, t} \\
c_{t} \geq r c\left(e_{t}+d_{e, t}\right)
\end{gathered}
$$

where $t c\left(e_{t}+d_{e, t}\right)$ is the amount of college tuition and fees, $\operatorname{gr}\left(e_{t}+d_{e, t}, s_{p}\right)$ is the amount of grants and scholarships which depend on schooling level and parental wealth, and $r c\left(e_{t}+d_{e, t}\right)$ denotes the cost of college room and board. We require that the consumption expenditure for those who choose to go to college must be no less than the cost of college room and board.

The budget constraint for an individual who is not currently enrolled in college (i.e., $\left.d_{e, t} \cdot \mathbf{1}\left(e_{t}+d_{e, t} \geq 13\right)=0\right)$ is:

$$
\begin{aligned}
c_{t}+s_{t+1} & =\left(1+r\left(s_{t}\right)\right) \cdot s_{t}+w_{t} \cdot h\left(d_{k, t}\right)+t r_{p, t}+t r_{c, t}+t r_{g, t} \\
c_{t} & \geq t r_{c, t} \\
c_{t} & \geq c_{\min }
\end{aligned}
$$

where $t r_{c, t} \geq 0$ is the direct consumption subsidy from the parents to their dependent child in the forms of shared housing and meals. ${ }^{11} c_{t} \geq t r_{c, t}$ requires that $t r_{c, t}$ only be a consumption subsidy. It cannot be used by the youth to finance his college expenses or pay back his debt. $t r_{g, t} \geq 0$ is the amount of government transfers, which consist of unemployment benefits and means-tested transfers that guarantee a minimum consumption floor $c_{m i n}$. Treating $c_{m i n}$ as

\footnotetext{
${ }^{10}$ Park (2016) finds that the source of parental transfer heterogeneity depends on factors that affect the total resources available to youth, such as parental wealth and altruism, and on factors that affect the monetary or psychic returns to education.

${ }^{11}$ It is only received when the child is age 17 and is not attending college.
} 
a subsistence level of consumption, we require $c_{t} \geq c_{\min }$.

\subsection{Model Solution}

The value function $V_{t}(\cdot)$ for $t=t_{0}, \ldots, T$ is characterized by the following Bellman equation:

$$
V_{t}\left(\boldsymbol{\Omega}_{t}\right)=\max _{d_{e, t}, d_{k, t}, s_{t+1}}\left\{U\left(c_{t}, d_{e, t}, d_{k, t} ; \boldsymbol{\Omega}_{t}\right)+\exp (-\rho(\boldsymbol{\theta})) \mathbb{E}\left(V_{t+1}\left(\boldsymbol{\Omega}_{t+1}\right) \mid \boldsymbol{\Omega}_{t}, e_{t+1}, s_{t+1}, k_{t+1}, d_{e, t}\right)\right\}
$$

subject to restrictions imposed by wage functions and human capital accumulation functions (Equations (3)-(6)), borrowing constraints (Equation (7)), and state-contingent budget constraints (Equation (9)-(13)).

The model is solved through numerical backward recursion of the Bellman equation assuming a terminal value function when the agent reaches age $T+1$. Ideally, we would like to choose a very large age for $T+1$. However, we also seek to avoid the computational burden of having to solve the model over long horizons. The initial age for our model is $t_{0}=17$. We set the terminal age to be $T+1=51$ so that individuals decisions during their 20 s are not sensitive to functional form assumptions about the terminal value function, and at the same time, the computational burden is also manageable. ${ }^{12}$

\subsection{Natural Borrowing Limit}

At age $t$, the smallest possible full-time wage earnings an individual receives is $F^{\psi}\left(e_{t}, k_{t}, \boldsymbol{\theta}, \underline{\epsilon}_{w}\right) \cdot h(1)$, where $\underline{\epsilon}_{w}$ is the worst possible productivity shock and $h(1)$ is full-time hours of work. The individual receives no wage income if he does not work.

To illustrate our approach, consider an extreme case where individuals supply their labor inelastically from period $t$ onwards, i.e, $d_{k, \tau}=1$ for all $\tau \geq t$. (This period comes after education decisions are made.) The natural borrowing limit in the private loan market in

\footnotetext{
${ }^{12}$ In comparison with previous studies, Keane and Wolpin (2001) approximate a terminal value function at age 31. Johnson (2013) approximates the terminal value function at age 40 .
} 
period $t-1$ in this extreme case is:

$$
\bar{L}_{t-1}^{s}\left(e, k_{t}, \boldsymbol{\theta}\right)=\frac{\bar{L}_{t}^{s}\left(e, k_{t}+1, \boldsymbol{\theta}\right)+\max \left\{0, F^{\psi}\left(e, k_{t}, \boldsymbol{\theta}, \underline{\epsilon}_{w}\right) \cdot h(1)-c_{\min }\right\}}{1+r_{b}} .
$$

When employment decisions are endogenous, the formulation of the natural borrowing limit requires further thought. Let the credit limit at time $t$ be $\bar{L}_{t}^{s}$ for an individual who does not work at $t$. The natural borrowing limit at period $t-1$ is (suppressing arguments) $\bar{L}_{t-1}^{s}=\bar{L}_{t}^{s} /\left(1+r_{b}\right)$. This can be interpreted as saying that individuals borrow new loans at time $t, \bar{L}_{t}^{s}$, to pay back debt $\left(1+r_{b}\right) \bar{L}_{t-1}^{s}$. At age $t$ the individual carries debt $s_{t+1}=-\bar{L}_{t}^{s} \leq 0$ and consumes government transfers $c_{t}^{u}=t r_{g, t} \geq c_{m i n}$. Let $C_{t}^{e v}$ be the compensation that makes an individual indifferent between working and not working. We implicitly define $C_{t}^{e v}$ as the solution to the following indifference relationship:

$$
\begin{aligned}
& u_{c}\left(C_{t}^{e v} ; \boldsymbol{\Omega}_{t}\right)+u_{k}\left(d_{k, t}=1, \boldsymbol{\Omega}_{t}\right) \\
& +\exp (-\rho(\boldsymbol{\theta})) \mathbb{E}\left(V_{t+1}\left(\boldsymbol{\Omega}_{t+1}\right) \mid \boldsymbol{\Omega}_{t}, e, s_{t+1}=-\bar{L}_{t}^{s}\left(e, F^{k}\left(k_{t}, d_{k, t}=1\right), \boldsymbol{\theta}\right), k_{t+1}=F^{k}\left(k_{t}, d_{k, t}=1\right)\right) \\
& =u_{c}\left(c_{t}^{u} ; \boldsymbol{\Omega}_{t}\right)+u_{k}\left(d_{k, t}=0, \boldsymbol{\Omega}_{t}\right) \\
& +\exp (-\rho(\boldsymbol{\theta})) \mathbb{E}\left(V_{t+1}\left(\boldsymbol{\Omega}_{t+1}\right) \mid \boldsymbol{\Omega}_{t}, e, s_{t+1}=-\bar{L}_{t}^{s}\left(e, F^{k}\left(k_{t}, d_{k, t}=0\right), \boldsymbol{\theta}\right), k_{t+1}=F^{k}\left(k_{t}, d_{k, t}=0\right)\right) .
\end{aligned}
$$

We require that the consumption compensation has to be at least equal to the subsistence level. Thus, if $C_{t}^{e v}<c_{\text {min }}$, we set $C_{t}^{e v}=c_{\text {min }}{ }^{13}$ As seen in Equation (14), $C_{t}^{e v}$ depends on the individual's psychic cost of working, and the future productivity gains of increased work experience, government transfers (including unemployment benefits), and the sustainable consumption level. In particular, the minimum consumption compensation $C_{t}^{e v}$ is high if (i) the individual's psychic cost of working $\left(-u_{k}\left(d_{k, t}=1, \Omega_{t}\right)+u_{k}\left(d_{k, t}=0, \Omega_{t}\right)\right)$ is high, (ii) the returns to work experience $\left(\mathbb{E}\left(V_{t+1}\left(\boldsymbol{\Omega}_{t+1}\right) \mid \Omega_{t}, e, s_{t+1}=-\bar{L}_{t}^{s}\left(e, F^{k}\left(k_{t}, d_{k, t}=1\right), k_{t+1}=\right.\right.\right.$ $\left.F^{k}\left(k_{t}, d_{k, t}=1\right)\right)-\mathbb{E}\left(V_{t+1}\left(\boldsymbol{\Omega}_{t+1}\right) \mid \boldsymbol{\Omega}_{t}, e, s_{t+1}=-\bar{L}_{t}^{s}\left(e, F^{k}\left(k_{t}, d_{k, t}=0\right), k_{t+1}=F^{k}\left(k_{t}, d_{k, t}=0\right)\right)\right)$

\footnotetext{
${ }^{13}$ In this case, given normality of goods, the first expression in (14) is bigger than the second expression and the agent always works.
} 
is low, and (iii) the government welfare subsidy $\left(c_{t}^{u}=t r_{g, t}\right)$ is high.

Equation (14) can be interpreted as an individual rationality constraint of working. The individual chooses to work only if his consumption level under working is at least $C_{t}^{e v}$. Under the most unfavorable possible income shocks, if wage earnings are higher than the consumption equivalence value, i.e., $F^{\psi}\left(e, k_{t}, \boldsymbol{\theta}, \underline{\epsilon}_{w}\right) \cdot h(1) \geq C_{t}^{e v}$, the individual works $d_{k, t}=1$ and the maximum amount of debt that he can pay back at age $t$ is $F^{\psi}\left(e, k_{t}, \boldsymbol{\theta}, \underline{\epsilon}_{w}\right) \cdot h(1)-C_{t}^{e v}$. This is the surplus of employment in terms of consumption value under the most unfavorable productivity shock. Using this notation, when an individual can choose between full-time working and not working, the individual's natural borrowing limit is:

$$
\begin{aligned}
& \bar{L}_{t-1}^{s}\left(e, k_{t}, \boldsymbol{\theta}\right)=\frac{\bar{L}_{t}^{s}\left(e, k_{t+1}, \boldsymbol{\theta}\right)+\max \left\{0, F^{\psi}\left(e, k_{t}, \boldsymbol{\theta}, \underline{\epsilon}_{w}\right) \cdot h(1)-C_{t}^{e v}\left(e, k_{t}, \boldsymbol{\theta}\right)\right\}}{1+r_{b}} \\
& k_{t+1}=F^{k}\left(k_{t}, d_{k, t}\right), \quad d_{k, t}=\mathbf{1}\left(F^{\psi}\left(e, k_{t}, \boldsymbol{\theta}, \underline{\epsilon}_{w}\right) \cdot h(1)-C_{t}^{e v}\left(e, k_{t}, \boldsymbol{\theta}\right) \geq 0\right) .
\end{aligned}
$$

It is straightforward to extend the previous derivation to take into account the part-time employment choices (or any discrete employment choices). Specifically, we define the employment specific consumption compensation $C_{t}^{e v}\left(d_{k, t} ; e, k_{t}, \boldsymbol{\theta}\right)$ associated with employment status $d_{k, t}$ as follows:

$$
\begin{aligned}
& u_{c}\left(C_{t}^{e v}\left(d_{k, t} ; e, k_{t}, \boldsymbol{\theta}\right) ; \boldsymbol{\Omega}_{t}\right)+u_{k}\left(d_{k, t}, \boldsymbol{\Omega}_{t}\right) \\
& +\exp (-\rho(\boldsymbol{\theta})) \mathbb{E}\left(V_{t+1}\left(\boldsymbol{\Omega}_{t+1}\right) \mid \boldsymbol{\Omega}_{t}, e, s_{t+1}=-\bar{L}_{t}^{s}\left(e, F^{k}\left(k_{t}, d_{k, t}\right), \boldsymbol{\theta}\right), k_{t+1}=F^{k}\left(k_{t}, d_{k, t}\right)\right) \\
& =u_{c}\left(c_{t}^{u} ; \boldsymbol{\Omega}_{t}\right)+u_{k}\left(0, \boldsymbol{\Omega}_{t}\right) \\
& +\exp (-\rho(\boldsymbol{\theta})) \mathbb{E}\left(V_{t+1}\left(\boldsymbol{\Omega}_{t+1}\right) \mid \boldsymbol{\Omega}_{t}, e, s_{t+1}=-\bar{L}_{t}^{s}\left(e, F^{k}\left(k_{t}, 0\right), \boldsymbol{\theta}\right), k_{t+1}=F^{k}\left(k_{t}, 0\right)\right) .
\end{aligned}
$$

Note that when $d_{k, t}=0, C_{t}^{e v}\left(d_{k, t}=0 ; e, k_{t}, \boldsymbol{\theta}\right)=c_{t}^{u}>0$ satisfying Equation (17) automatically. 
Thus, the endogenous borrowing limit as defined in this paper is:

$\bar{L}_{t-1}^{s}\left(e, k_{t}, \boldsymbol{\theta}\right)=\frac{\bar{L}_{t}^{s}\left(e, k_{t+1}, \boldsymbol{\theta}\right)+\max \left\{0,\left[F^{\psi}\left(e, k_{t}, \boldsymbol{\theta}, \underline{\epsilon}_{w}\right) F^{w}\left(\tilde{d}_{k, t}, 0\right) \cdot h\left(\tilde{d}_{k, t}\right)-C_{t}^{e v}\left(\tilde{d}_{k, t} ; e, k_{t}, \boldsymbol{\theta}\right)\right]\right\}}{1+r_{b}}$

$\tilde{d}_{k, t}=\arg \max _{d_{k, t} \in\{0,0.5,1\}}\left\{\mathbf{1}\left(d_{k, t}>0\right)\left(F^{\psi}\left(e, k_{t}, \boldsymbol{\theta}, \underline{\epsilon}_{w}\right) F^{w}\left(d_{k, t}, 0\right) \cdot h\left(d_{k, t}\right)-C_{t}^{e v}\left(d_{k, t} ; e, k_{t}, \boldsymbol{\theta}\right)\right)\right\}$

$k_{t+1}=F^{k}\left(k_{t}, \tilde{d}_{k, t}\right)$.

Equations (18) and (20) imply that if $\left(F^{\psi}\left(e, k_{t}, \boldsymbol{\theta}, \underline{\epsilon}_{w}\right) F^{w}\left(d_{k, t}, 0\right) \cdot h\left(d_{k, t}\right)-C_{t}^{e v}\left(d_{k, t} ; e, k_{t}, \boldsymbol{\theta}\right)\right)<$ 0 for $d_{k, t}>0$, then $\tilde{d}_{k, t}=0, \bar{L}_{t-1}^{s}\left(e, k_{t}, \boldsymbol{\theta}\right)=\frac{\bar{L}_{t}^{s}\left(e, k_{t+1}, \boldsymbol{\theta}\right)}{1+r_{b}}$, and $k_{t+1}=F^{k}\left(k_{t}, 0\right)$.

At terminal age $T, \bar{L}_{T}(\cdot)=0$, we calculate $C_{T}^{e v}(\cdot)$ using Equation (17). We then calculate the natural borrowing limit $\bar{L}_{T-1}(\cdot)$ at $T-1$ based on Equations (18) to (20). Using Equations (17)-(20), we calculate the natural borrowing limit recursively at any age.

The natural borrowing limit derived in our model implies that at a given age, an individual's borrowing limit is lower if (i) the individual has a low level of human capital, (ii) the individual's psychic cost of working is higher, (iii) the returns to work experience are lower, and (iv) the government welfare subsidy for not working is higher. An agent's human capital affects his borrowing limit by affecting his future earning capacity $\left\{F_{t}^{\psi}(\cdot)\right\}_{t}$. The individual's psychic cost of working, the future productivity gains of increased work experience, and government welfare policy affect borrowing limits by affecting the minimum consumption compensation level $C_{t}^{e v}$.

\subsection{Discussion of the Natural Borrowing Limit}

The concept of the natural borrowing limit was first proposed in Aiyagari (1994). ${ }^{14} \mathrm{He}$ defines the natural borrowing limit as the maximum amount an individual can repay with certainty. The underlying regime that would generate this constraint is one in which lenders

\footnotetext{
${ }^{14}$ Huggett (1993) develops a model with incomplete-insurance where agents faces a borrowing constraint of one year's income.
} 
can fully enforce contracts and collect on all resources available to the individual. ${ }^{15}$

Our notion of the natural borrowing limit extends Aiyagari's borrowing limit by considering endogenous labor supply and human capital investment. Following Aiyagari (1994), we assume that lenders can fully enforce contracts and can collect from all resources available to the individual. Borrowers must repay as long as they have resources. However, different from Aiyagari, who assumes that earnings are exogenous, in our model labor supply is endogenous and lenders cannot force borrowers to work. Since borrowers always have the choice not to work and collect welfare covering their minimum consumption requirement, lenders can never drive borrower's utility below that value or they will collect nothing. Hence, the lending regime with endogenous labor supply is that lenders can enforce full repayment subject to the restriction that borrowers must be provided a minimum consumption level $\left(C_{t}^{e v}\right.$ defined by Equation (17)) that satisfies the borrower's individual rationality constraint of working.

Our formulation of the borrowing limit, that takes into account individual decisions about labor supply and human capital accumulation, is related to studies that assume imperfectly enforceable contracts (see Marcet and Marimon (1992), Kehoe and Levine (1993), Albuquerque and Hopenhayn (2004), and Cooley et al. (2004), Cagetti and De Nardi (2006)). Imperfect enforceability of contracts means that the creditors are not able to force the debtors to fully repay their debts as promised and that the debtors fully repay only if it is in their own interest to do so. Since both parties are aware of this feature and act rationally, the lender will lend to a given borrower only an amount (possibly zero) that will be in the debtor's interest to repay as promised.

Our natural borrowing limit does not depend on parental transfers. In our model, parental financial transfers $t r_{p, t}$ are governed by a stochastic transfer rule. The lowest possible value of parental financial transfers (regardless of the youth's choices) is zero, which consequently implies that the youths cannot credibly promise to pay back positive loans using (possibly

\footnotetext{
${ }^{15}$ It is one motive for precautionary saving (see Zeldes, 1989).
} 
zero) parental transfers with certainty. Parental consumption transfer $t r_{c, t}$ is in the form of shared housing and meals provided by their parents. Youth cannot "cash" such consumption subsidy to pay back their debt. Regarding government transfers, we assume that private lenders cannot touch government transfers including tuition subsidies and grants. Hence the formation of the natural borrowing limit does not take into account government transfers. However, both parental and governmental transfers affect labor supply decisions and accumulated work experience, and hence indirectly affect the natural borrowing limit.

We implicitly assume that borrowers can costlessly signal their private information to lenders so that there is no asymmetric information in the lending market. Examples of such signals include past history of wage earnings, employment, criminal background, test scores on cognitive ability, and FICO scores, etc. Any restrictions that reduce an individual's ability to signal his own type will result in asymmetric information in the lending market and may reduce the amount of the borrowing limits for the most able individuals. ${ }^{16}$

Our analysis differs from Navarro and Zhou (2016), who estimate a model with a version of an Aiyagari borrowing constraint. ${ }^{17}$ They assume, in our notation, that $\bar{L}_{t}^{s}(e)=$ $Y_{T+1}^{M I N}(e) /\left(1+r_{b}\right)^{T+1-t}$, where $Y_{T+1}^{M I N}(e)>0$ is the social security income after retirement that depends on education. They assume that agents always work a minimum number of hours. They do not account for individual rationality constraints of working in their formulation of borrowing limits. The decision to work does not affect private debt limits. They do not allow for post-schooling human capital accumulation nor do they account for

\footnotetext{
${ }^{16}$ Our extension of the Aiyagari credit constraint does not capture the full array of credit market possibilities facing agents. They may go bankrupt with varying penalties ranging from full market exclusion (Alvarez and Jermann, 2001) to a range of other possible penalties (Chatterjee et al., 2007). Lenders can monitor and adjust period-by-period loans based on employment and medical histories, and other events realized by agents (see Chatterjee et al., 2007 and Jermann and Quadrini, 2012). A variety of financial arrangements are available to lenders and borrowers (see Gertler and Kiyotaki, 2010). Lenders can monitor borrowers and demand collateral or some form of enforceable partial repayment conditions. The assumption that the only binding constraint facing agents is that they must repay debt in the terminal period (up to some limit) is surely an extreme simplification of a richer set of period-by-period market and default opportunities. Moreover, it assumes some implicit mechanism through which agents comply with a no-terminal-default rule. We thank Dean Corbae, Jorge García, and Lars Hansen for stimulating conversations on these issues.

${ }^{17}$ Terminal assets must be no less than a particular lower bound.
} 
access to student loans, heterogeneity in parental transfers, and heterogeneity in parental characteristics.

In contrast, our formulation of the borrowing limit extends Aiyagari's borrowing limit into the realm of imperfectly enforceable contracts where agents' decision to work, the psychic cost of working, unobserved ability, and endogenous human capital accumulation (both in terms of education and work experience) directly affect the private debt limit.

Our analysis differs from the approaches of Keane and Wolpin (2001) and Johnson (2013) by not introducing additional free parameters from outside the model to proxy unmeasured credit constraints. Ours is a far more stringent approach to estimation. Finally, unlike other approaches in the literature, we do not specify ad hoc fixed credit limits (see, for example, Abbott et al., 2016) or calibrate the model to fit asset distributions. Table 1 summarizes how the literature models credit constraints and our distinct approach to modeling them.

\subsection{Optimal Decisions}

The envelope condition is:

$$
\frac{\partial V_{t}}{\partial s_{t}}=\lambda_{b, t}\left(1+r\left(s_{t}\right)\right), \quad \text { if } s_{t} \neq 0
$$

where $r\left(s_{t}\right)=r_{l} \mathbf{1}\left(s_{t}>0\right)+r_{b} \mathbf{1}\left(s_{t}<0\right)$ and $\lambda_{b, t}$ is the Lagrange multiplier associated with the budget constraint.

The first-order conditions with respect to $c_{t}>0$ and $s_{t+1} \neq 0, t<T$ are:

$$
\begin{aligned}
\frac{\partial u_{c}\left(c_{t} ; \boldsymbol{\Omega}_{t}\right)}{\partial c_{t}} & =\lambda_{b, t} \\
\exp (-\rho(\boldsymbol{\theta}))\left(\frac{\partial \mathbb{E} V_{t+1}}{\partial s_{t+1}}\right)+\lambda_{s, t} & =\lambda_{b, t}
\end{aligned}
$$

where $\lambda_{s, t}$ is the Kuhn-Tucker multiplier of the borrowing constraint. If $\lambda_{s, t}>0$, the borrowing constraint binds, i.e., $s_{t+1}=\underline{S}_{t+1}$. If $\lambda_{s, t}=0$, the borrowing constraint does not bind and the individual is able to smooth consumption between ages $t$ and $t+1$. 
Individuals value education and work experience not only because they improve productivity and earnings, but because they increase the natural borrowing limit and thus provide insurance values for consumption against adverse wage shocks. The first order conditions are consistent with agent rationality associated with the employment choices.

\subsection{Initial Conditions and Our Measurement System}

We complete the specification of our model by defining initial conditions and a set of measurement equations that relate proxied cognitive and noncognitive endowments to a set of observed measures. Individuals start life as autonomous agents at age $17\left(t_{0}=17\right)$. The age 17 information set, $\bar{\Omega}_{17}$, is:

$$
\bar{\Omega}_{17}:=\left(17, \theta_{c}, \theta_{n}, k_{17}, e_{17}, s_{17}, d_{e, 16}, e_{p}, s_{p}\right)
$$

The initial condition at age 17 that can be determined from sample information are: ${ }^{18}$

$$
\overline{\mathbf{\Omega}}_{17}^{\text {observed }}:=\left(17, k_{17}, e_{17}, s_{17}, d_{e, 16}, e_{p}, s_{p}\right)
$$

We proxy $\boldsymbol{\theta}$ but do not directly observe it.

The joint distribution of unobserved ability at initial age 17, conditional on parental background at $17\left(X_{17}\right)$ is given by:

$$
\left(\begin{array}{c}
\theta_{c} \\
\theta_{n}
\end{array}\right) \mid X_{17} \sim N\left(\left(\begin{array}{l}
\mu_{c}\left(e_{p}, s_{p}\right) \\
\mu_{n}\left(e_{p}, s_{p}\right)
\end{array}\right),\left(\begin{array}{cc}
\sigma_{c}^{2} & \sigma_{c, n} \\
\sigma_{c, n} & \sigma_{n}^{2}
\end{array}\right)\right)
$$

where $\mu_{j}\left(e_{p}, s_{p}\right)=\mu_{j}+\mu_{j, e, 1} \mathbf{1}\left(e_{p}=12\right)+\mu_{j, e, 2} \mathbf{1}\left(e_{p}>12 \& e_{p}<16\right)+\mu_{j, e, 3} \mathbf{1}\left(e_{p} \geq 16\right)+$ $\mu_{j, s, 1} \mathbf{1}\left(s_{p}=2\right.$ nd Tercile $)+\mu_{j, s, 2} \mathbf{1}\left(s_{p}=3\right.$ rd Tercile $)$, for $j=c, n$. Thus we allow the initial distribution to differ by parents' wealth and education to capture early parental investment

\footnotetext{
${ }^{18}$ Education, lagged school attendance, parental education, and parental wealth $\left(e_{17}, d_{e, 16}, e_{p}, s_{p}\right)$ are observed in our sample. We also set the accumulated years of working experience and net worth at age 17 to be zero $\left(k_{17}=0, s_{17}=0\right)$.
} 
due to parents' financial resources, knowledge, or preferences.

We lack direct measurements of cognitive and noncognitive endowments. Instead, we observe a set of measurement equations for $\boldsymbol{\theta}$. Specifically, we assume that at age 17 there are two sets of dedicated measurement equations for $\left(\theta_{c}, \theta_{n}\right)$ given by Equations $(24)$ and (25), respectively

$$
\begin{array}{ll}
Z_{c, j}^{*}=\mu_{z, c, j}+\alpha_{z, c, j} \theta_{c}+\epsilon_{z, c, j}, & j \in\left\{1, \ldots, J_{c}\right\} \\
Z_{n, j}^{*}=\mu_{z, n, j}+\alpha_{z, n, j} \theta_{n}+\epsilon_{z, n, j}, & j \in\left\{1, \ldots, J_{n}\right\}
\end{array}
$$

where individual control variables, including parental education, parental wealth, and the individual's age in 1997 are omitted from the measurement equations. The measurement errors $\epsilon_{z, c, j}$ and $\epsilon_{z, n, j}$ are assumed to be independently distributed within and across each block of measurements. The distribution of $\left(\theta_{c}, \theta_{n}\right)$ is assumed to be jointly normal. To incorporate both continuous and binary measurements, we assume that the following relationship holds for each measurement at every point of time:

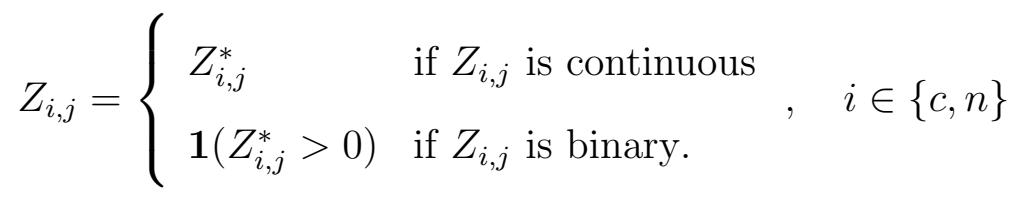

\section{Data and Preliminary Regression Analysis}

We estimate the model using data from the National Longitudinal Survey of Youth 1997 (NLSY97). The NLSY97 is a nationally representative sample of approximately 9,000 youths born during the years 1980 through 1984. Over the sample period 1997 to 2013, the NLSY97 provides extensive information every year on the respondents' schooling, employment, earnings, and monetary transfers from parents and government. It also provides individual information on cognitive skills, earlier-life adverse behaviors, and parental education and wealth.

We restrict our sample to white males, so our estimates of inequality are not affected by 
issues of race or gender. We use the unweighted data. ${ }^{19}$ Our final sample contains 2,102 individuals, with 25,639 individual-year observations. Table A1 in the Web Appendix reports the number of observations dropped in each step of our sample selection.

\subsection{Variable Description}

\section{Measures of Cognitive Ability and Noncognitive Ability}

We use the Armed Services Vocational Aptitude Battery (ASVAB) scores as measures of cognitive ability. ${ }^{20}$ Specifically, we consider the scores from Mathematical Knowledge (MK), Arithmetic Reasoning (AR), Word Knowledge (WK), and Paragraph Comprehension (PC). These four scores have been used by NLSY staff to create the Armed Forces Qualification Test (AFQT) score, which is commonly used in the literature as a measure of IQ or cognitive ability. ASVAB scores are only asked in the year 1999.

Our measures of noncognitive ability include three variables that indicate respondents' adverse behaviors at very early ages. Specifically, we use violent behavior in 1997 (have ever attacked anyone with the intention of hurting or fighting), theft behavior in 1997 (have ever stolen something worth $\$ 50$ or more), and any sexual intercourse before age 15 . Individuals with high noncognitive ability are less likely to display adverse behaviors. (See Heckman and Kautz, 2014 and Kautz and Zanoni, 2015 for discussions of these measures and their validity.)

\section{Education and Labor Market Outcomes}

Education is measured by the highest grade completed. We manually recode this variable by cross-checking the highest grade completed with data on enrollment and the highest degree received, in order to correct for missing data, data coding errors, and GEDs. In particular, a high school dropout with a GED is recoded to his highest grade of school actually completed.

\footnotetext{
${ }^{19}$ See Johnson (2013) for the same procedure.

${ }^{20}$ The CAT-ASVAB is an automated computerized test developed by the United States Military which measures overall aptitude. The test is composed of 12 subsections and has been well-researched for its ability to accurately capture the aptitude of test-takers.
} 
The NLSY97 records the number of hours worked in each week, the number of weeks worked in a year, and total income earned in a year. We define full-time working to be working no less than 30 hours a week, and part-time working to be working less than 30 hours a week but more than or equal to 10 hours a week. Among workers aged 23 and above, the average full-time employment annual hours of work is 2,314 and the median is 2,184, and the average part-time annual hours of work is 998 and the median is 1,040. Frequency distributions of weeks and hours worked are provided in the Web Appendix Figure A1. For employed workers, the hourly wage rate is the ratio between total earned income and total actual hours worked (in 2004 dollars).

The NLSY97 collects detailed information on assets and debts of respondents at ages 20, 25, and 30. We define net worth as all assets (including housing assets and all financial assets) minus all debt (including mortgages and all other debts). ${ }^{21}$

\section{Parental Education, Net Worth, and Transfers}

The NLSY97 asks each respondent about their parents' schooling and net worth information only in round 1 (1997). We define parents' education as the average years of schooling of father and mother if both the father's and mother's schooling are available. ${ }^{22}$ For singleparent families where only one parent's schooling level is available, we define the parents' schooling only using the single parent's schooling level. Parents' net worth is defined as all assets (including housing assets and all financial assets) minus all debt (including mortgages and all other debts). Parental transfer data is constructed as total monetary transfers received from parents in each year, including allowance, non-allowance income, college financial

\footnotetext{
${ }^{21}$ In our sample, the bottom $1 \%$ of net worth is $-\$ 42,028$ and the bottom $5 \%$ is $-\$ 6,604$. The net worth is skewed to the right, the median net worth is $\$ 8,504$, the top $10 \%$ of the net worth is $\$ 80,630$, and the top $5 \%$ is $\$ 146,364$. We bottom-code the net worth to be $-\$ 75,000$ and top-code the net worth to be $\$ 100,000$. In Johnson (2013), asset values are top coded at $\$ 45,000$ and bottom coded at $-\$ 35,000$ for NLSY97 males aged 18 to 26 .

${ }^{22}$ We top-code parents years of schooling to be 16 years (4-year college graduate) and bottom code parents schooling to be 8 years (high school dropouts).
} 
aid gift, and inheritance. ${ }^{23}$

\subsection{Summary Statistics}

Table 2: Key Variables over Age

\begin{tabular}{lcccc}
\hline \hline & Age 17 & Age 20 & Age 25 & Age 30 \\
\hline In School & 0.87 & 0.37 & 0.10 & 0.01 \\
Full-Time Working & 0.04 & 0.44 & 0.73 & 0.78 \\
Part-Time Working & 0.49 & 0.30 & 0.12 & 0.06 \\
Part-Time Working While in School & 0.46 & 0.24 & 0.07 & 0.03 \\
Education & 10.34 & 12.25 & 13.43 & 13.78 \\
Years Worked & 0.00 & 0.77 & 3.92 & 8.05 \\
Net Worth & 0.00 & 13467.81 & 20569.12 & 34826.70 \\
Full-Time Hourly Wage & 6.10 & 9.55 & 14.71 & 18.25 \\
Part-Time Hourly Wage & 6.16 & 8.46 & 15.28 & 15.77 \\
Receive Parental Transfers & 0.37 & 0.46 & 0.18 & 0.06 \\
Total Parental Transfers & 428.53 & 1766.64 & 315.89 & 83.51 \\
\hline \hline
\end{tabular}

Table 3: Measures of Cognitive and Noncognitive Ability (Year 1997)

\begin{tabular}{lccccc}
\hline \hline & mean & $\mathrm{sd}$ & $\min$ & $\max$ & $\mathrm{N}$ \\
\hline ASVAB: Arithmetic Reasoning (1997) & -0.08 & 0.95 & -3.14 & 2.37 & 1,786 \\
ASVAB: Mathematics Knowledge (1997) & 0.06 & 0.98 & -2.80 & 2.68 & 1,781 \\
ASVAB: Paragraph Comprehension (1997) & -0.16 & 0.93 & -2.36 & 1.83 & 1,784 \\
ASVAB: Word Knowledge (1997) & -0.28 & 0.89 & -3.15 & 2.35 & 1,785 \\
Noncognitive: Violent Behavior (1997) & 0.22 & 0.42 & 0.00 & 1.00 & 2,097 \\
Noncognitive: Had Sex Before Age 15 & 0.18 & 0.38 & 0.00 & 1.00 & 2,100 \\
Noncognitive: Theft Behavior (1997) & 0.10 & 0.30 & 0.00 & 1.00 & 2,098 \\
\hline \hline
\end{tabular}

\footnotetext{
${ }^{23}$ College financial aid gift includes any financial aid respondents received from relatives and friends that are not expected to be paid back for each college and term attended in each school year.
} 
Figure 1: Parental Monetary Transfers By Parental Characteristics

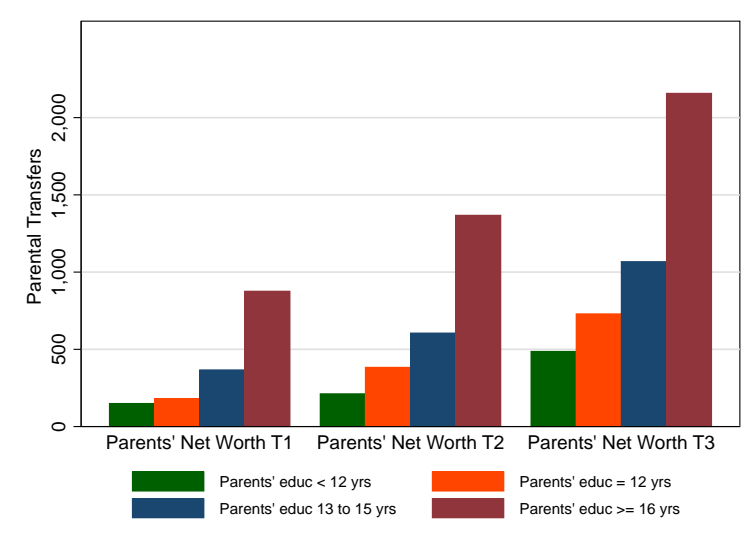

(a) By Parents' Net Worth Terciles \& Education

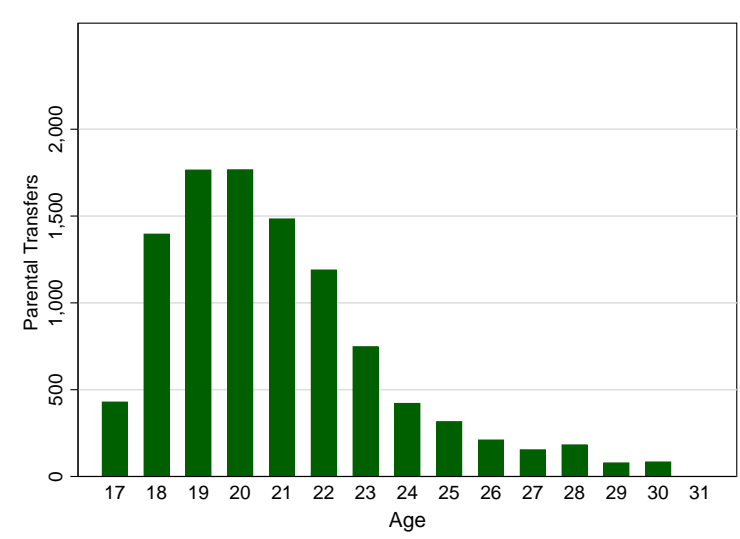

(b) By Youth's Age

Source: NLSY97. Parental transfer is the total monetary transfers received from parents in each year, including allowance, non-allowance income, college financial aid gift, and inheritance.

Table 2 reports the statistics of key variables by age. ${ }^{24}$ At age $17,87 \%$ of the youth are enrolled in school, and the fraction of the youth in school decreases to $10 \%$ at age 25 . The fraction of the youth who work full time steadily increases from $44 \%$ at age 20 to $78 \%$ at age 30; the fraction of part-time employment decreases from $30 \%$ at age 20 to $6 \%$ at age 30. Average years of schooling increase from 10.3 at age 17 to 13.8 at age 30 . The average net worth increases from $\$ 13,468$ at age 20 to $\$ 34,827$ at age 30 . Average hourly wages (both part-time job and full-time job) increase between age 17 and age 30. Average full-time hourly wage rate is $\$ 18$ at age 30. All the variables are measured in 2004 dollars. Table A3 reports average years of work experience, wages, and net worth for 4 education groups at age 25. Measures of cognitive and noncognitive skills at age 17 are presented in Table 3 .

\footnotetext{
${ }^{24}$ The summary statistics for the entire sample over year 1997 to 2011 is reported in Table A2.
} 
Figure 2: Relationships Between Early Endowments and Environments and College Choices

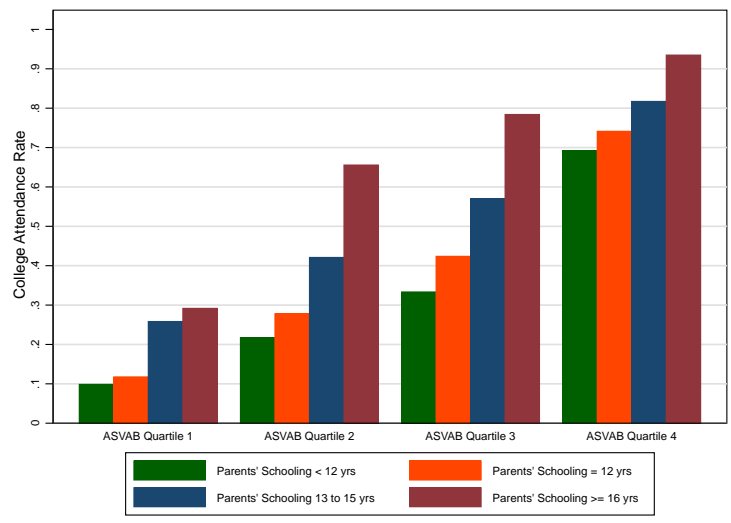

(a) College Attendance by Parental Education

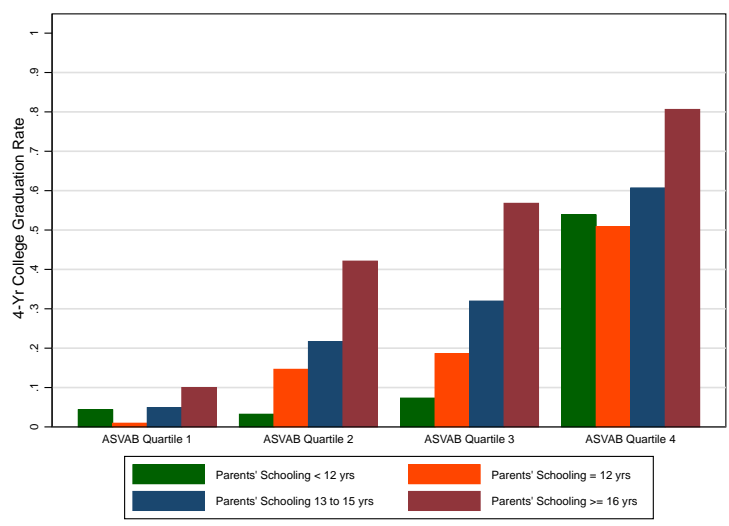

(c) 4-Year College Grad. by Parental Education

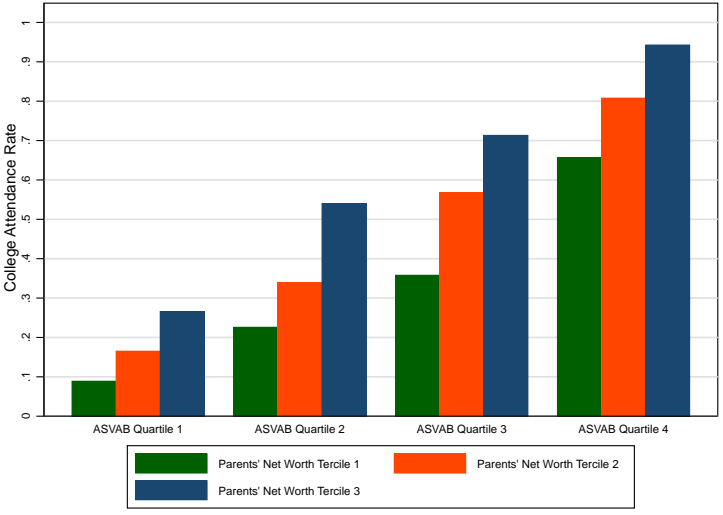

(b) College Attendance by Parental Net Worth

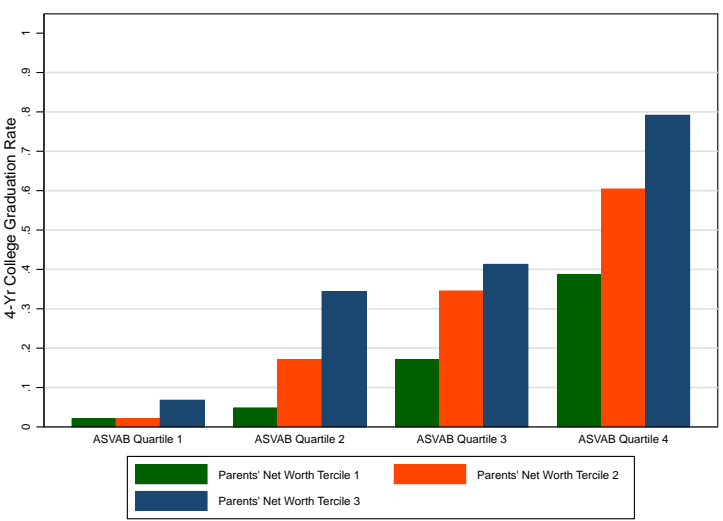

(d) 4-Year College Grad. by Parental Net Worth

Source: NLSY97 white males. 4-Year college graduate rate is calculate as the fraction of individual whose years of schooling are more than or equal to 16 at age 25 .

The distribution of parental transfers is skewed. ${ }^{25}$ The amount of parental transfers to children is either positive or zero. On average, $29 \%$ of the youths receive zero monetary transfers from their parents. Among those who receive positive parental transfers, the average amount of transfers received is $\$ 3,116$, and the median amount is $\$ 907$. As shown in Figure 1, on average, the amount of parental transfers depends crucially on parental education and net worth and varies over the youth's life cycle.

\footnotetext{
${ }^{25}$ Conditional on parental transfers being positive, the top 1 percentile of the parental transfers amount is $\$ 24,639$. We top-code the maximum amount of positive parental transfers to be $\$ 30,000$ per year.
} 
There is a positive impact of parental education and wealth on educational decisions. As seen in Figure 2, even after controlling for measures of the youths' own cognitive ability, there is still a strong positive correlation between parents' education and net worth and an individual's college attendance and 4-year college completion. Table 4 reports the OLS regression results of years of schooling at age 30 on ASVAB, the number of early adverse behaviors, parental education, and parental net worth. After controlling for the ASVAB score, individuals' years of schooling are still positively correlated with both parental education and parental net worth. Furthermore, college attendance decisions are negatively correlated with the number of early adverse behaviors, which suggests a positive correlation between years of schooling and noncognitive ability. ${ }^{26}$

Table 4: OLS Regression of Adult Educational Outcomes on Early Endowment and Family Influence

\begin{tabular}{lcc}
\hline \hline & \multicolumn{2}{c}{ Education } \\
\hline ASVAB & $1.03^{* * *}$ & $(0.03)$ \\
Num of Adverse Behaviors & $-0.60^{* * *}$ & $(0.04)$ \\
Parents' Education & $0.27^{* * *}$ & $(0.02)$ \\
Parents' Net Worth 2nd Tercile & $0.67^{* * *}$ & $(0.07)$ \\
Parents' Net Worth 3rd Tercile & $1.12^{* * *}$ & $(0.07)$ \\
Age & $0.09^{* * *}$ & $(0.02)$ \\
\hline$R^{2}$ & 0.46 & \\
Observations & 5354 & \\
\hline \hline
\end{tabular}

Standard errors in parentheses.

Source: NLSY97 white males aged 25 to 30 .

${ }^{*} p<0.10,{ }^{* *} p<0.05,{ }^{* * *} p<0.01$

\section{$5 \quad$ Empirical Strategy}

The precise specifications used to estimate our model are reported in Section 5.1. ${ }^{27}$ In Section 5.2, we discuss calibration of parameters that are identified using externally supplied data. After that, we turn to consider model identification (Section 5.3) and estimation (Section 5.4).

\footnotetext{
${ }^{26}$ Table A4 reports the OLS estimation results for logarithm of hourly wages among individuals who always work after leaving school upon completing the highest degree.

${ }^{27}$ Web Appendix Section A.2 gives the parameterization of the parental transfer function.
} 


\subsection{Model Parameterization}

We use the following additively separable current flow utility function:

$$
U\left(c_{t}, d_{e, t}, d_{k, t} ; \boldsymbol{\Omega}_{t}\right)=\frac{\left(c_{t} / e s_{t, e}\right)^{1-\gamma}-1}{1-\gamma}+u_{e}\left(\boldsymbol{\Omega}_{t}\right) d_{e, t}+u_{k}\left(d_{k, t}, d_{e, t}, \boldsymbol{\Omega}_{t}\right)
$$

where $e s_{t, e}$ is the equivalence scales of family size, ${ }^{28} u_{e}\left(\boldsymbol{\Omega}_{t}\right)$ and $u_{k}\left(d_{k, t}, d_{e, t}, \boldsymbol{\Omega}_{t}\right)$ are flow utility (or disutility if negative) associated with individual choices of schooling and working, respectively:

$$
\begin{aligned}
& u_{e}\left(\boldsymbol{\Omega}_{t}\right)=\phi_{e, 0} \mathbf{1}\left(d_{e, t}+e_{t} \leq 12\right)+\left(\phi_{e, 1}+\phi_{e, a} \mathbf{1}(t>22)\right) \cdot \mathbf{1}\left(d_{e, t}+e_{t}>12 \& d_{e, t}+e_{t} \leq 16\right) \\
& \quad+\phi_{e, 2} \mathbf{1}\left(d_{e, t}+e_{t}>16\right)+\alpha_{e, c} \theta_{c}+\alpha_{e, n} \theta_{n}+\phi_{e, p} \mathbf{1}\left(e_{p} \geq 16\right)-\phi_{e, e}\left(1-d_{e, t-1}\right)+\sigma_{e} \epsilon_{e, t} \\
& u_{k}\left(d_{k, t}, d_{e, t}, \boldsymbol{\Omega}_{t}\right)=\left[\phi_{k, e} \cdot \mathbf{1}\left(d_{k, t}=0.5 \& d_{e, t}=1\right)+\phi_{k, 0} \cdot \mathbf{1}\left(d_{k, t}=0.5 \& d_{e, t}=0\right)\right. \\
& \left.\quad+\left(\phi_{k, 1}+\phi_{k, 2}(a g e-17)\right) \cdot \mathbf{1}\left(d_{k, t}=1\right)\right] \cdot\left(1+\alpha_{k, c} \theta_{c}+\alpha_{k, n} \theta_{n}\right)
\end{aligned}
$$

where the schooling preference shock $\epsilon_{e, t}$ is i.i.d. standard normal distributed.

We allow for the psychic costs of schooling to depend on an individual's cognitive and noncognitive abilities. $\phi_{e, 0}, \phi_{e, 1}$, and $\phi_{e, 2}$ characterizes the level of psychic costs for attending high school, college, and graduate school, respectively. $\phi_{e, a}$ is the psychic cost of late enrollment in college, and $\phi_{e, e}$ is the psychic cost of re-entering school. We also introduce preference heterogeneity in schooling depending on parental education level $e_{p}$ to allow for the direct impact of parental education on schooling $\left(\phi_{e, p}\right)$. We allow for preference shocks to the utility of schooling $\left(\epsilon_{e, t}\right)$.

Parameters $\phi_{k, e}, \phi_{k, 0}$, and $\phi_{k, 1}$ govern the level of psychic costs of part-time working while in school, part-time working while not in school, and full-time working, respectively.

\footnotetext{
${ }^{28}$ Household equivalence scales measure the change in consumption expenditures needed to keep the welfare of a family constant when its size varies. We calculate the equivalence scales of different household sizes following Fernández-Villaverde and Krueger (2007). For example, this scale implies that a household of two needs 1.34 times the consumption expenditure of a single household. We do not model endogenous changes in family size. Instead we allow family size to vary exogenously depending on education level $e$ and age $t$. The average family size for each education group at every age is obtained from CPS data 1997 to 2012.
} 
We allow the preference of full-time working to vary with age $\left(\phi_{k, 2}\right)$. We also allow the psychic costs of working to depend on an individual's cognitive and noncognitive abilities.

Following Gourinchas and Parker (2002) and De Nardi (2004), we assume that the terminal value function at age $T+1$ takes the following functional form:

$$
V_{T+1}\left(\boldsymbol{\Omega}_{T+1}\right)=\phi_{s} \frac{\left(s_{T+1} / e s_{T, e}\right)^{1-\gamma}-1}{1-\gamma},
$$

where $\phi_{s}$ characterizes the influence of net worth at age $T+1$. Equation (30) approximates an individual's value function at age $T+1$. It does not imply that individuals die at age $T+1$ or that other state variables in $\boldsymbol{\Omega}_{T+1}$ do not matter. It just implies that the marginal effects of other state variables (such as accumulation of education and experience) on the individual's value function at age $T+1$ are small. As noted in Section 3.7, we set the terminal age to be $T+1=51$.

We allow the subjective discount rate $\rho\left(\theta_{c}, \theta_{n}\right)$ to depend on cognitive ability and noncognitive ability:

$$
\rho\left(\theta_{c}, \theta_{n}\right)=\rho_{0}\left(1-\rho_{c} \theta_{c}-\rho_{n} \theta_{n}\right)
$$

An individual's wage function and human capital function are characterized by:

$$
\begin{aligned}
& \log w_{t}=\log \psi_{t}+\mathbf{1}\left(d_{k, t}=0.5\right)\left(\beta_{w, 0}+\beta_{w, 1} d_{e, t}\right) \\
& \text { where }
\end{aligned}
$$

$$
\begin{aligned}
\log \psi_{t}= & \beta_{\psi, 0}+\beta_{\psi, k} k_{t}+\beta_{\psi, k k} k_{t}^{2} / 100+\beta_{\psi, e, 0}\left(e_{t}-12\right) \\
& +\beta_{w, e, 1} \mathbf{1}\left(e_{t}=12\right)+\beta_{w, e, 2} \mathbf{1}\left(e_{t}>12 \& e_{t}<16\right)+\beta_{w, e, 3} \mathbf{1}\left(e_{t} \geq 16\right) \\
& +\left(\alpha_{\psi, c, 0} \theta_{c}+\alpha_{\psi, n, 0} \theta_{n}\right) \cdot \mathbf{1}\left(e_{t}<12\right) \\
& +\left(\alpha_{\psi, c, 1} \theta_{c}+\alpha_{\psi, n, 1} \theta_{n}\right) \cdot \mathbf{1}\left(e_{t} \geq 12 \& e_{t}<16\right) \\
& +\left(\alpha_{\psi, c, 2} \theta_{c}+\alpha_{\psi, n, 2} \theta_{n}\right) \cdot \mathbf{1}\left(e_{t} \geq 16\right)+\epsilon_{w, t}-\mathbb{E}\left(\epsilon_{w, t}\right)
\end{aligned}
$$

where $\epsilon_{w, t}$ is the education specific idiosyncratic productivity shock. We allow the density 
function of $\epsilon_{w, t}$ to differ depending on whether the individual has a four-year college degree or not.

Without loss of generality, we normalize the lowest possible value of $\epsilon_{w, t}$ to be $0: \underline{\epsilon}_{w}=0$. We assume that the productivity shock $\epsilon_{w, t} \geq \underline{\epsilon}_{w}=0$ is drawn from a gamma distribution $\operatorname{Gamma}(a, b)$ with the following density function:

$$
p\left(\epsilon_{w, t}\right)=\frac{1}{\Gamma(a) b^{a}}\left(\epsilon_{w, t}\right)^{a-1} e^{-\left(\epsilon_{w, t}\right) / b}
$$

Therefore, $E\left(\epsilon_{w, t}\right)=a b$ and $\operatorname{Var}\left(\epsilon_{w, t}\right)=a b^{2}$. The gamma distribution allows us to flexibly model both the shape and the scale of the productivity shock distribution which are governed by the parameters $a$ and $b$, respectively. ${ }^{29}$

\subsection{External Calibration}

For parameters that can be identified outside the structural model, such as the monetary cost of schooling and government transfers, we rely on external data sources. Table 5 summarizes all the parameters that are externally specified in our structural model. We now discuss these choices in detail.

We calculate the cost of college tuition and fees and grants and scholarships from the following two sources: (i) Total direct expenditures (including tuition and fees) of higher education level $e_{t}$ are calculated as the average expenditures per student using data from The Integrated Postsecondary Education Data System (IPEDS); (ii) The average amount of the grant for each education level associated with every parental net worth tercile using the NLSY97 sample. We also obtain the average cost of college room and board from IPEDS for two-year college and 4-year college, respectively.

We set the borrowing interest rate equal to 5 percent annually. We set the lending interest rate $r_{l}$ to be 1 percent annually, which is the average real interest rate on 1-year

\footnotetext{
${ }^{29}$ Chatterjee et al. (2007) assume that the distribution function of $\epsilon_{w, t}$ is characterized by a one-parameter distribution function: $\operatorname{Prob}\left(\epsilon_{w} \leq z\right)=\left(\frac{z-\epsilon_{w}}{\bar{\epsilon}_{w}-\underline{\epsilon}_{w}}\right)^{\phi_{w}}$, where $\phi_{w}$ controls the shape of the shock distribution and $\bar{\epsilon}_{w}$ is the upper bound of the shock. Our specification is more flexible.
} 
Table 5: Parameters Calibrated Outside the Structural Model

\begin{tabular}{|c|c|c|c|}
\hline Description & Parameter & Value & Source \\
\hline College Tuition \& Fees & $\begin{array}{l}t c(e=13,14) \\
t c(e \geq 15)\end{array}$ & $\begin{array}{c}\$ 5,073 \\
\$ 10,653\end{array}$ & $\begin{array}{l}\text { IPEDS data on average tuition and fees } \\
\text { 1999-2006. }\end{array}$ \\
\hline $\begin{array}{l}\text { College Grants and } \\
\text { Scholarship }\end{array}$ & $\begin{array}{l}\operatorname{gr}\left(e=13,14, s_{p}=T 1\right) \\
\operatorname{gr}\left(e=13,14, s_{p}=T 2\right) \\
\operatorname{gr}\left(e=13,14, s_{p}=T 3\right) \\
\operatorname{gr}\left(e \geq 15, s_{p}=T 1\right) \\
\operatorname{gr}\left(e \geq 15, s_{p}=T 2\right) \\
\operatorname{gr}\left(e \geq 15, s_{p}=T 3\right)\end{array}$ & $\begin{array}{l}\$ 2,581 \\
\$ 2,287 \\
\$ 2,476 \\
\$ 3,604 \\
\$ 2,569 \\
\$ 2,607\end{array}$ & $\begin{array}{l}\text { NLSY97 data on average grants and } \\
\text { scholarship by years of schooling and } \\
\text { parental wealth terciles. }\end{array}$ \\
\hline College Room and Board & $\begin{array}{l}r c(e=13,14) \\
r c(e \geq 15)\end{array}$ & $\begin{array}{l}\$ 4,539 \\
\$ 6,532\end{array}$ & $\begin{array}{l}\text { Johnson (2013) room and board for 2-year } \\
\text { college and 4-year college }\end{array}$ \\
\hline $\begin{array}{l}\text { GSL Borrowing Annual } \\
\text { Limit }\end{array}$ & $\begin{array}{l}\bar{l}^{g}(e=13) \\
\bar{l}^{g}(e=14) \\
\bar{l}^{g}(e=15,16) \\
\bar{l}^{g}(e>16)\end{array}$ & $\begin{array}{c}\$ 2,625 \\
\$ 3,500 \\
\$ 5,500 \\
\$ 10,500\end{array}$ & Annual Stafford Loan Limits 1993 to 2007 \\
\hline $\begin{array}{l}\text { GSL Borrowing Aggregate } \\
\text { Limit }\end{array}$ & $\begin{array}{l}\bar{L}^{g}(e \geq 13 \& e \leq 16) \\
\bar{L}^{g}(e \geq 16)\end{array}$ & $\begin{array}{l}\$ 23,000 \\
\$ 138,500\end{array}$ & $\begin{array}{l}\text { Undergraduate } \\
\text { Graduate + Undergraduate }\end{array}$ \\
\hline $\begin{array}{l}\text { Borrowing Interest Rate } \\
\text { Lending Interest Rate }\end{array}$ & $\begin{array}{l}r_{b} \\
r_{l}\end{array}$ & $\begin{array}{l}5 \% \\
1 \%\end{array}$ & $\begin{array}{l}\text { Federal Student Aid } \\
\text { Average real interest rate on 1-year } \\
\text { U.S. government bonds from } 2001 \text { to } \\
2007\end{array}$ \\
\hline $\begin{array}{l}\text { Parental Transfer } \\
\text { Function }\end{array}$ & $\operatorname{tr}_{p}\left(e_{p}, s_{p}, d_{e, t}, d_{k, t}, e_{t}, t\right)$ & $\begin{array}{l}\text { Table } \\
\text { A5 }\end{array}$ & NLSY97 sample \\
\hline $\begin{array}{l}\text { Parents Consumption } \\
\text { Subsidy }\end{array}$ & $t r_{c, t}=\chi \cdot \mathbf{1}(t<18)$ & $\$ 7,800$ & Kaplan (2012) \& Johnson (2013) \\
\hline $\begin{array}{l}\text { Part-time Annual Hours } \\
\text { Full-time Annual Hours }\end{array}$ & $\begin{array}{l}h(0.5) \\
h(1)\end{array}$ & $\begin{array}{l}1,040 \\
2,080\end{array}$ & $\begin{array}{l}20 \text { hours per week, } 52 \text { weeks } \\
40 \text { hours per week, } 52 \text { weeks }\end{array}$ \\
\hline Unemployment Benefit & $\begin{array}{l}b_{g}(e \leq 12) \\
b_{g}(e \geq 13 \& e \leq 16) \\
b_{g}(e>16)\end{array}$ & $\begin{array}{l}\$ 540 \times 3 \\
\$ 600 \times 3 \\
\$ 740 \times 3\end{array}$ & NLSY97 UI benefits \\
\hline $\begin{array}{l}\text { Minimum Consumption } \\
\text { Floor }\end{array}$ & $c_{\min }$ & $\$ 2,800$ & $\begin{array}{l}\text { NLSY sample average means-tested } \\
\text { transfers among recipients }\end{array}$ \\
\hline Risk Aversion Coefficient & $\gamma$ & 2.0 & $\begin{array}{l}\text { Lochner and Monge-Naranjo (2012) } \\
\text { and Johnson (2013) }\end{array}$ \\
\hline Terminal Value function & $\phi_{s}$ & 25.0 & PSID 1999-2011: $\operatorname{Median}\left(s_{51} / c_{50}\right)=5$ \\
\hline
\end{tabular}

IPEDS = Integrated Postsecondary Education Data System. Average tuition and fees are weighted by fulltime enrollment and are deflated in 2004 dollars. Because expenditures are higher at four-year institutions than at two-year institutions, there is a noticeable jump in cost between two and three years of college. Within our sample period, the aggregate subsidized Stafford Loan Limits is $\$ 23,000$ for undergraduate and $\$ 138,500$ for graduate and undergraduate in total. The Interest rate ranges from 3.34 to $8.25 \%$ for Stafford Loans over the time period 1997 to 2011. Parental consumption subsidy is given by $t r_{c, t}=\chi \cdot \mathbf{1}(t<18)$, where $\chi$ is the value of direct consumption subsidy provided by the parents such as shared housing and meals when the youth attends high school. 
U.S. government bonds from 2001 to 2007. Note that the interest rate spread on borrowing and lending $(4 \%)$ is quite large and already embodies an important market friction.

We estimate the logarithm of parental monetary transfers, $\log \left(t_{p, t}+1\right)$ using our NLSY97 sample (see Section A.2 in the Web Appendix for parameterization); the parameter estimates are reported in Web Appendix Table A5. In the sample, 94\% of youth who are attending high school live with their parents. ${ }^{30}$ Following Kaplan (2012) and Johnson (2013), we set the consumption subsidy provided by parents for those who are living with their parents and not attending school, $\chi$, to be $\$ 650$ monthly ( $\$ 7,800$ annually $)^{31} ; \chi$ includes both the direct and indirect costs of housing as well as shared meals.

We set the hours of work to be 20 hours per week for part-time jobs and 40 hours per week for full-time jobs (see Keane and Wolpin (2001)), therefore the annual hours of work is 1,040 hours for part-time job and 2,080 hours for full-time job. ${ }^{32}$ We set the monthly unemployment benefits to be $\$ 540$ for unemployed workers without a college degree, $\$ 600$ for some college or 4-year college workers, and $\$ 740$ for workers with a graduate degree. ${ }^{33}$ We assume that unemployed workers can receive unemployment benefits for 3 months. In our sample, the average amount of means-tested transfers (including food stamps, AFDC and WIC) among recipients is about $\$ 2,800$ annually. Thus, we set the government means-tested minimum consumption floor $c_{\min }$ to be $\$ 2,800$.

We set the relative risk aversion parameter to be $\gamma=2.0$ following Lochner and MongeNaranjo (2011) and Johnson (2013). A majority of existing microstudies on consumption and savings estimate the value of $\gamma$ to be between one and three. ${ }^{34}$

\footnotetext{
${ }^{30}$ The ratio is $42 \%$ for those who are not attending high school.

${ }^{31}$ Our model abstracts away from multiple child households.

${ }^{32}$ In our sample, among workers aged 23 and above, the median annual working hours of a part-time worker is 1,040 and the median annual working hours of a full-time employed worker is 2,184.

${ }^{33}$ Conditional on receiving unemployment benefits, the mean monthly unemployment insurance benefits are $\$ 800$ for workers with at most a high school degree, $\$ 900$ for workers with some college or 4-year college, and $\$ 1,100$ for workers with a graduate degree. In the model, we assume individuals who are not working or in school receive unemployment benefits, which are substantially more generous than the actual unemployment benefits; we thus reduce the predicted unemployment benefits amount by one-third following Kaplan (2012).

${ }^{34}$ See Browning et al. (1999) for a summary of the early literature.
} 
To calibrate the parameter in the terminal value function, we note that the first-order optimal condition at age $T$ can be written as $c_{T}{ }^{-\gamma}=\phi_{s} s_{T+1}{ }^{-\gamma}$. From the Panel Study of Income Dynamics (PSID) 1999 to 2011 the median value of $\frac{s_{T+1}}{c_{T}}$ is 5.0 among households whose head aged $T+1=51,{ }^{35}$ therefore we set $\phi_{s}=\left(\frac{s_{T+1}}{c_{T}}\right)^{\gamma}=(5.0)^{\gamma}=25.0$.

\subsection{Identification}

This section discusses identification of key features of the model.

\subsubsection{Factor Model and Measurement System}

The identification of factor models requires normalizations that set the location and scale of the factors (see Anderson and Rubin (1956)). For each factor $\left(\theta_{c}, \theta_{n}\right)$, we normalize its unconditional mean to be zero, i.e., $E_{e_{p}, s_{p}}\left(\theta_{c}\right), E\left(\theta_{c}\right)=E\left(\theta_{n}\right)=0$, and standard deviation to be one, i.e., $\sigma_{c}=\sigma_{n}=1$. We allow intercepts in all measurement equations.

\subsubsection{Dynamic Model and Structural Parameters}

This section provides an overview of identification of the structural model. The parameters that remain to be identified are: 15 parameters characterizing individual preferences over schooling and working, 20 parameters characterizing the human capital production function (including the density function of productivity shocks) and wage function, and 3 parameters regarding discount factors.

The parameters on the subjective discount rate can in principle be identified by using consumption data formed from the asset data. To illustrate, consider the Euler equation under a CRRA utility specification for those who are far away from borrowing constraints (abstracting from uncertainty): ${ }^{36}$

$$
\gamma \cdot\left(\log c_{t+1}-\log c_{t}\right)=-\rho\left(\theta_{c}, \theta_{n}\right)+\log (1+r)
$$

\footnotetext{
${ }^{35}$ To be consistent with our net worth measure in the data section, we also measure net worth as all assets (including housing assets and all financial assets) minus all debts (including mortgages and all other debts) in PSID.

${ }^{36}$ For illustrative purposes, here we assume $u_{c}\left(c_{t} ; \boldsymbol{\Omega}_{t}\right)=c_{t}^{1-\gamma} / 1-\gamma$ and $r$ is the borrowing/lending interest rate.
} 
using the fact that $\gamma$ is set externally. ${ }^{37}$ The identification of the parameters of the subjective discount rate function $\rho$ relies on variations in consumption growth and thus savings. The level of average net worth identifies the constant term of the subjective discount rate, $\rho_{0} \cdot{ }^{38}$

Identification of the rest of the model can be justified using the analysis of Heckman and Navarro (2007) and Heckman et al. (2016). Under large support conditions and conditional independence assumptions, we can determine an unconstrained set of agents with access to full insurance (Arrow-Debreu insurance) who always work and are not subject to credit constraints. With $\gamma$ in hand (by assumption) and the discount factors known (by the previous analysis), we can monetize the consumption value of future income flows and can follow the two cited papers in using earnings data to identify psychic costs of education. Using the parameters so determined, we can use the full data set to estimate psychic costs of work and the parameters of the labor supply function. We identify the human capital accumulation equations by conditioning on $\boldsymbol{\theta}$ estimated from the preceding analysis (see e.g., Heckman et al., 2013).

\subsection{Estimation Method}

We use a two-step estimation procedure. In the first step, we estimate the parameters of the measurement system and the joint distribution of cognitive ability and noncognitive ability at age 17, using simulated maximum likelihood:

$$
\max \Pi_{i} \int_{\theta_{c}, \theta_{n}} f\left(Z_{i} ; X_{i}, \theta_{c}, \theta_{n}\right) d F\left(\theta_{c}, \theta_{n}\right) .
$$

The initial conditions for cognitive ability and noncognitive ability in the second step are obtained by simulation using the parameter estimates from the first step.

In the second step, we use the method of simulated moments to estimate parameters of individual preferences (15 parameters), human capital production function and wage equation

\footnotetext{
${ }^{37}$ Potentially, if $r$ varies we can identify $\gamma$.

${ }^{38}$ Alternatively, if we fix $\rho$ externally, we can identify $\gamma$.
} 
(20 parameters), and discount factors (3 parameters). ${ }^{39}$ In total, we estimate 38 parameters in the second step using a total number of moments of 222. Table 6 lists targeted moments, which includes choices probabilities and outcome variables over age and by education categories as well as conditional moments between outcome variables and measures of cognitive and noncognitive abilities. We use diagonal moments of the data following Altonji and Segal (1996). The weighting matrix is the inverse of the diagonal matrix of the variance-covariance matrix of the data moments.

\section{Estimation Results}

This section discusses our estimates. Sections 6.1 and 6.2 discuss the parameter estimates and the goodness of model fit respectively. Section 6.3 presents the estimated natural borrowing limits. Section 6.4 presents the fraction of youths who are estimated to be credit constrained by age, by endowment, and by human capital levels. Section 6.5 discusses the sorting patterns into education based on unobserved cognitive ability and noncognitive ability. Section 6.6 discuss the inequality in human capital, education, and consumption in the estimated model (baseline case).

\subsection{Parameter Estimates}

\subsubsection{Measurement System Parameters}

The distribution of $\left(\theta_{c}, \theta_{n}\right)$ is reported in Web Appendix Table A6. The parameter estimates of the measurement equations are reported in Table A7. The two initial endowments are positively correlated with each other. ${ }^{40}$ The correlation between cognitive ability and noncognitive ability is $0.280 .^{41}$

\footnotetext{
${ }^{39}$ The choice variables in the model include not only discrete controls such as schooling and working decisions but also continuous controls such as asset level. As a result, we use Simulated Method of Moments (SMM) to estimate the model.

${ }^{40}$ The variance of each factor is normalized to one for identification.

${ }^{41}$ Heckman et al. (2016) report an estimate of .40 for a related model.
} 
Table 6: Targeted Moments for SMM Estimation

\begin{tabular}{|c|c|}
\hline Targeted Moments & \# Moments \\
\hline \multicolumn{2}{|l|}{$\begin{array}{l}\text { Choice probabilities, state variables, and outcome variables over the life- } \\
\text { cycle }\end{array}$} \\
\hline Probabilities of schooling for each age 17 to 30 & 14 \\
\hline Probabilities of working part-time for each age 17 to 30 & 14 \\
\hline Probabilities of working full-time for each age 17 to 30 & 14 \\
\hline Average hourly full-time wage for each age 18 to 30 & 13 \\
\hline Average hourly part-time wage for each age 18 to 30 & 13 \\
\hline Average net worth at ages 20,25 , and 30 & 3 \\
\hline Average negative net worth at ages 20,25 , and 30 & 3 \\
\hline Average years of schooling at age 30 & 2 \\
\hline Average years of work experience at age 30 & 2 \\
\hline Probability of enrolling in college at age 21 & 1 \\
\hline Probability of graduating from 4 -year college at age 25 & 1 \\
\hline Average years of work experience if working full time at age 30 & 1 \\
\hline Probability of working part-time while in school at ages 18 to 22 & 1 \\
\hline Average log wage rate when working in school at ages 18 to 22 & 1 \\
\hline Probabilities of high school, some college, and 4-year college at ages 25 and 30 & $3 \times 2$ \\
\hline Probabilities of years of school more than 16 years at age 30 & 1 \\
\hline Variance of log earnings at age 30 & 1 \\
\hline Variance of log hourly wage at age 30 & 1 \\
\hline Variance of log years of schooling at age 30 & 1 \\
\hline Variance of log experience at age 30 & 1 \\
\hline
\end{tabular}

Covariance terms from auxiliary models (Indirect Inference)

Regression coefficients of log hourly wage on work experience, work experience squared, years of schooling, HSG, SCL , CLG, cognitive ability $\times$ HSD, noncognitive ability $\times$ HSD, cognitive ability $\times$ HSG, noncognitive ability $\times$ HSG, cognitive ability $\times$ SCL, noncognitive ability $\times$ SCL, cognitive ability $\times$ CLG, noncognitive ability $\times$ CLG, previously not working, constant; and standard deviation of regression residual Regression coefficients of school enrollment on previous period's enrollment status, 6 age, age $=17$, parents' education, cognitive ability, noncognitive ability

Regression coefficients of full-time working on years of schooling, cognitive ability, 3 noncognitive ability

Regression coefficients of log net worth on cognitive ability, noncognitive ability, and 6

log wage, age $\geq 20$, age $\geq 25$, constant

Conditional moments for each of the 4 education categories

Average net worth by 4 education categories at ages 25 and $30 \quad 4 \times 2$

Average negative net worth by 4 education categories at ages 25 and $30 \quad 4 \times 2$

Average log hourly wage by 4 education categories at ages 25 and $30 \quad 4 \times 2$

Standard deviation of log hourly wage by 4 education categories at ages 25 and $30 \quad 4 \times 2$

Median log hourly wage by 4 education categories at ages 25 and $30 \quad 4 \times 2$

Bottom 5 percentile of log hourly wage by 4 education categories at ages 25 and $30 \quad 4 \times 2$

Top 5 percentile of log hourly wage by 4 education categories at ages 25 and $30 \quad 4 \times 2$

Average hourly full-time wage by 4 education categories at ages 25 and $30 \quad 4 \times 2$

Average hourly wage by 4 education categories at ages 25 and $30 \quad 4 \times 2$

Average years of work experience by 4 education categories at ages 25 and $30 \quad 4 \times 2$

Probability of working part-time by 4 education categories at ages 25 and $30 \quad 4 \times 2$

Probability of working full-time by 4 education categories at ages 25 and $30 \quad 4 \times 2$ 


\subsubsection{Structural Model Parameters}

Web Appendix Table A8 reports preference parameter estimates for the schooling utility functions (Panel A) and work utility function (Panel B). The psychic benefit of schooling is higher for individuals with higher cognitive and noncognitive abilities. Individuals whose parents have higher levels of education also have higher flow utility from schooling. The parameter estimates suggest that the psychic cost of working part-time while in school $\left(\phi_{k, e}=\right.$ $-0.0773)$ is higher than the psychic cost of part-time working while not in school $\left(\phi_{k, 0}=\right.$ -0.0332). In our estimation, we do not impose any restrictions on the relative magnitudes of these two parameters. Forcing the psychic cost of working part-time while in school to be the same as the psychic cost of part-time working while not in school overpredicts the fraction of working students in school.

Parameter estimates of the discount rate function are reported in Table A9. Figure 3 plots the density of estimated discount factors in the benchmark model. Appendix Figure A4 plots the density of estimated discount factor for high ability and low ability, separately. As expected, individuals with higher levels of cognitive ability and/or noncognitive ability have considerably lower rates of time preference.

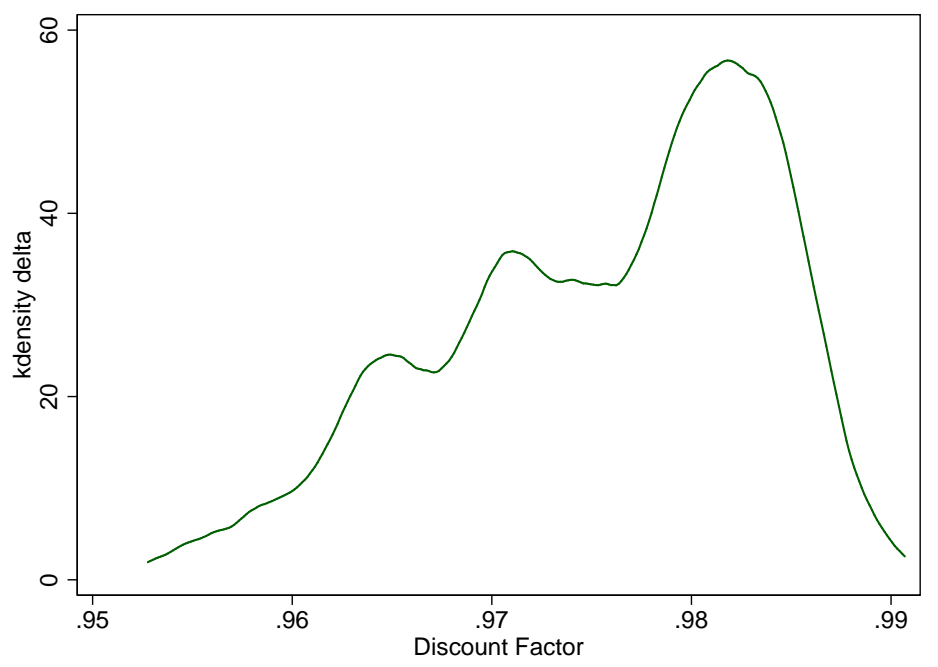

Figure 3: Density of Estimated Discount Factors: $\exp \left(-\rho\left(\theta_{c}, \theta_{n}\right)\right)$ 


\subsubsection{Labor Market Skill Production and Wages}

Table A10 in the Web Appendix reports parameter estimates for the human capital production function and the wage equation. A one standard deviation increase in cognitive ability increases an individual's human capital level as well as offered wages by $\left(\alpha_{\psi, c, 2}=0.1433\right) \log$ points among 4-year college graduate workers. The effects of noncognitive ability on human capital levels and wages are small and not statistically different from zero.

\subsection{Model Goodness of Fit}

In this section, we report the goodness of model fit on selected target moments (Table 6 gives the complete set of targeted moments). Our model closely fits the lifecycle patterns of school enrollment (Figure 4(a)) and employment (see Figures 4(b) and 4(c)). Figure 4(d) shows that our estimated model fits the observed accepted wage patterns over time. Figures 4(e) and 4(f) plot our model fits of average net worth and average negative net worth $\left(s_{t} \mathbf{1}\left(s_{t}<0\right)\right)$ at ages 20,25 , and $30 .^{42}$

As shown in Figure 5, our model can replicate the patterns of number of years worked for each of the four education categories at age 30. Our model can also replicate the average wages for each education category at age 30 .

\footnotetext{
${ }^{42}$ Figures A5 in the Web Appendix plots the model fit on years of schooling over age, over parent's education categories, and over parents' net worth terciles. The fit is generally good.
} 


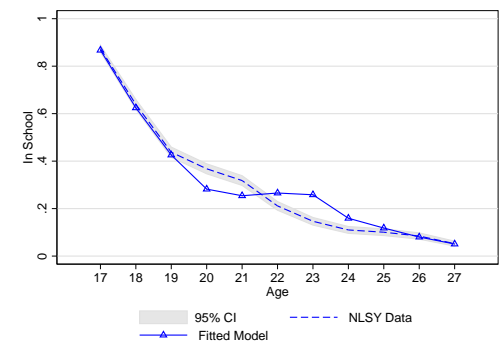

(a) In School

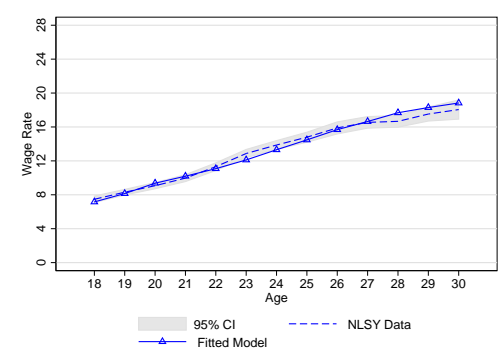

(d) Hourly Wages over Age

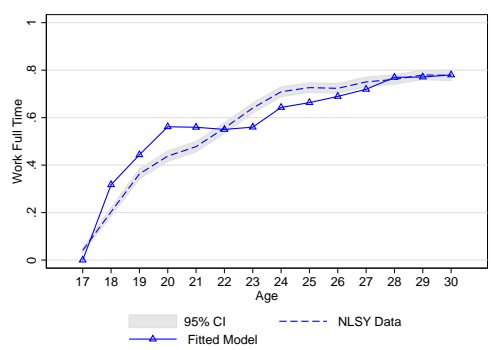

(b) Working Full-time

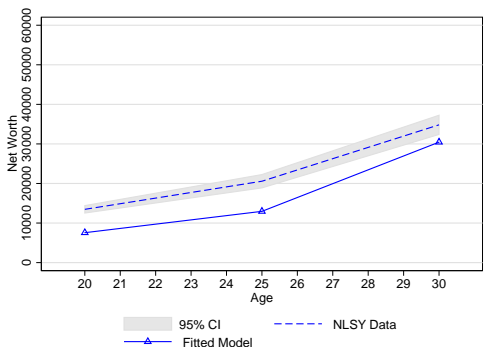

(e) Net Worth by Age

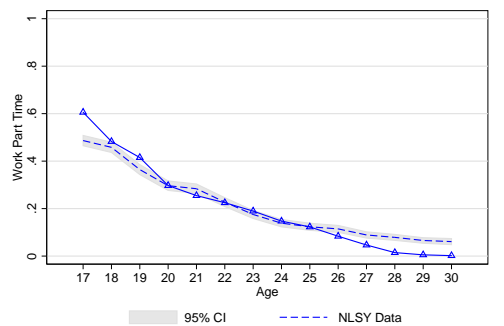

$95 \% \mathrm{Cl}$
$\triangle \quad$ Fitted Mode

(c) Working Part-time

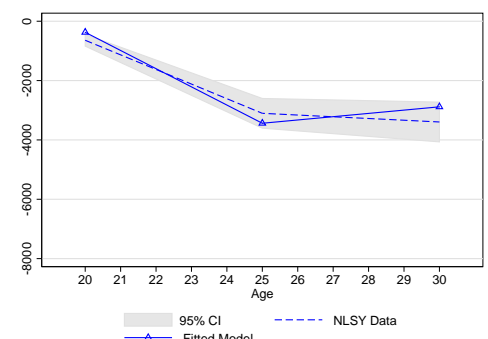

(f) Negative Net Worth by Age

Figure 4: Model Fit over the Lifecycle

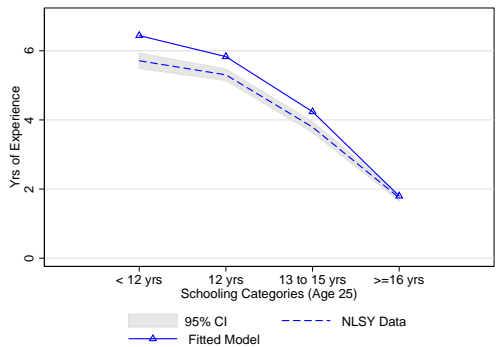

(a) Yrs Worked by Education

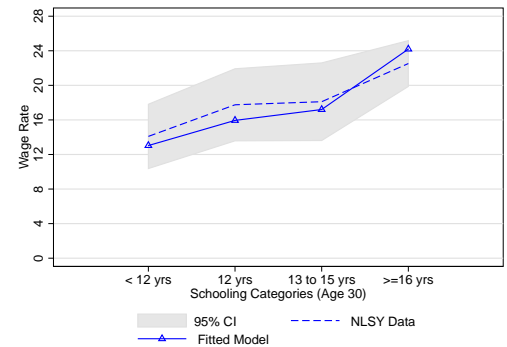

(b) Hourly Wages by Education

Figure 5: Model Fit by Education

Tables A11 and A12 in the Web Appendix report model fits for the covariance terms from auxiliary models for enrollment and employment, respectively. Table A13 in the Web Appendix reports model fits of the auxiliary model for log hourly wage. Table A14 in the Web Appendix shows the model fits of the auxiliary model for log net worth. Our model generally fits the data well. 


\section{$6.3 \quad$ Natural Borrowing Limit $\bar{L}_{t}^{s}$}

Figure 6(a) plots both the average amount of natural borrowing limit for all individuals from age 17 to age 50. The mean natural borrowing limit at first increases as an individual accumulates schooling and work experience, and then gradually decreases as individuals age and remaining lifetime earnings declines. ${ }^{43}$ Such a pattern is in sharp contrast with that of a life cycle model without human capital accumulation in the absence of life cycle wage growth in which the natural borrowing limit decreases monotonically with age.

Next, we explore the relationship between an individual's natural borrowing limit in the private lending market $\bar{L}_{t}^{s}\left(e_{t+1}, k_{t+1}, \boldsymbol{\theta}\right)$ and his human capital $\psi_{t}=F^{\psi}\left(e_{t}, k_{t}, \boldsymbol{\theta}, \epsilon_{t}\right)$ at age t. Figure 6(b) plots the model implied average natural borrowing limit over log human capital levels at age 30 . The average natural borrowing limit is relatively flat with respect to an individual's human capital level when the human capital level is low. For agents with a very low human capital level, natural borrowing limits are zero. This is because, in the presence of the worst possible labor market shock, agents with very low human capital would just choose to not work and live off welfare. When the human capital level is higher, the natural borrowing limit increases with the human capital level. Similarly, conditional on age, the natural borrowing limit generally increases with education, cognitive ability, and noncognitive ability (see Web Appendix Figure A15).

We plot the evolution of natural borrowing limits with age for individuals with different cognitive and noncognitive abilities in Figure 7. The natural borrowing limits generally increases with age during the period age 17 to 30 . However, the growth rate of the natural borrowing limit is much higher for individuals with higher initial ability endowments.

\subsection{Borrowing Constrained Youths}

An important contribution of our model is the estimation of life cycle credit constraints governing behavior. Using our model, we can calculate the fraction of individuals who are

\footnotetext{
${ }^{43}$ The decline to zero at age 50 is an artifact of our assumed horizon of 51 years. The figure is qualitatively correct for later terminal ages but shifts the hump rightward.
} 


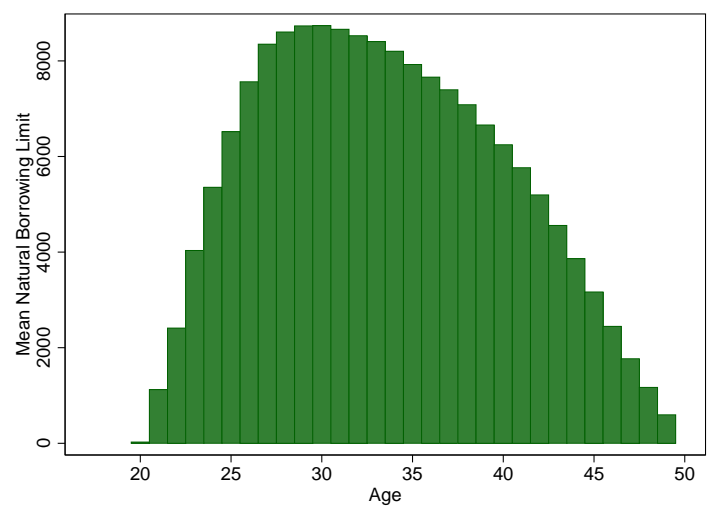

(a) Natural Borrowing Limit over Ages 17 to 50

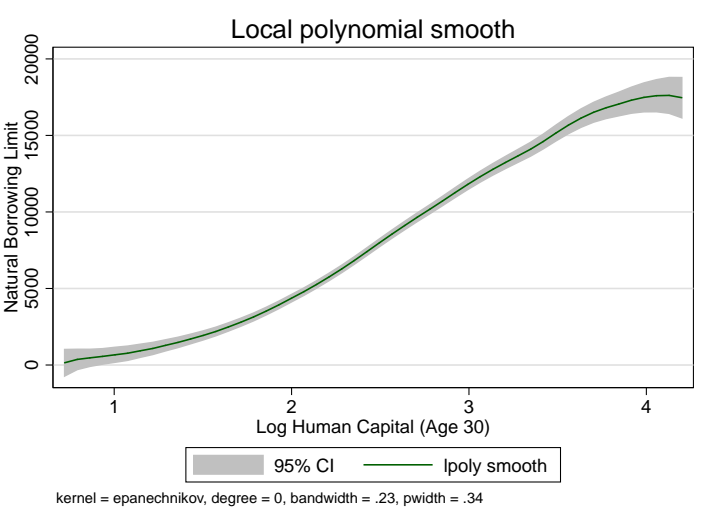

(b) Natural Borrowing Limit vs Human Capital at Age 30

Figure 6: Mean of Natural Borrowing Limit $\bar{L}_{t}^{s}\left(e_{t+1}, k_{t+1}, \boldsymbol{\theta}\right)$

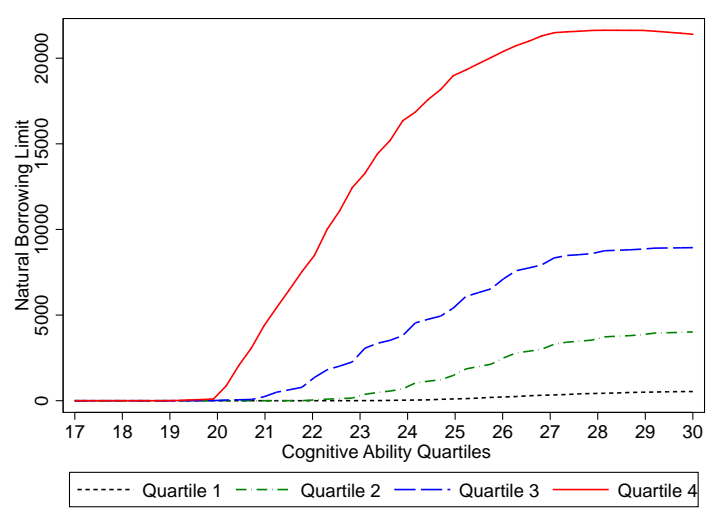

(a) Natural Borrowing Limit vs Cognitive Ability

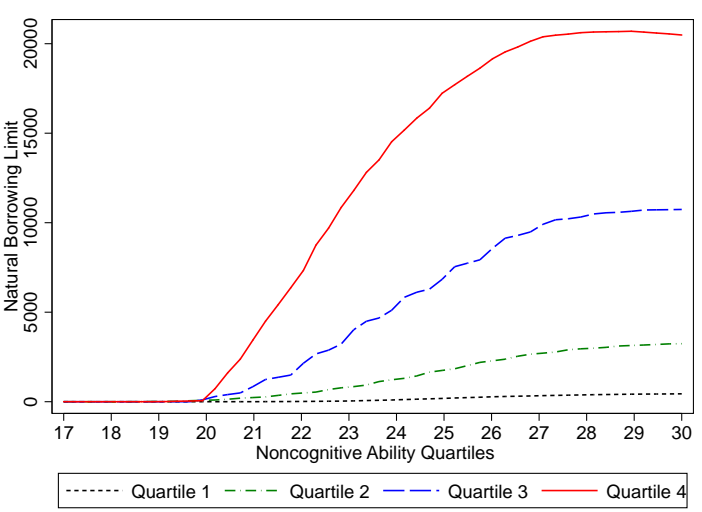

(b) Natural Borrowing Limit vs Noncog. Ability

Figure 7: Evolution of Average Natural Borrowing Limit by Ability Endowments 
borrowing-constrained by evaluating the Kuhn-Tucker multiplier associated with an individual's optimal savings decision. In particular, using the first order conditions from an individual's optimization problem (Equations (22) and (23)), we can calculate the KuhnTucker multiplier associated with individuals' next period asset decisions as follows:

$$
\lambda_{s, t}\left(c_{t}, s_{t+1} ; \boldsymbol{\Omega}_{t}\right)=\frac{\partial u_{c}\left(c_{t} ; \boldsymbol{\Omega}_{t}\right)}{\partial c_{t}}-\exp \left(-\rho\left(\theta_{c}, \theta_{n}\right)\right)\left(\frac{\partial \mathbb{E} V_{t+1}}{\partial s_{t+1}}\right)
$$

We define an individual as borrowing constrained at period $t$ if $\lambda_{s, t}>0$ and $s_{t+1} \leq$ $-\bar{L}_{t}^{s}\left(e_{t+1}, k_{t+1}, \boldsymbol{\theta}\right)$. Figures 8, 9, and 10 graph — at ages 21, 30, and 40, respectively - the model predicted fraction constrained as functions of various arguments. Appendix Figures A7, A8, and A9 graph the multipliers $\left(\lambda_{s, t}\right)$ in the model simulated data as a function of the same arguments. Figures 8(b), 9(b), and 10(b) report fraction constrained by levels of cognitive ability. Figures $8(d), 9(d)$, and 10(d) report fraction constrained by the logarithm of human capital stocks.

At age 21, these graphs exhibit a weak bimodality that sharpens somewhat by age 30 . Two groups of people are constrained. Many agents with low ability and low human capital endowments have relatively flat life cycle wage growth. There are also some with high ability and high human capital endowments with high wage growth who, in their 20s and early 30s, cannot fully access their future income because of borrowing restrictions. By age 40 (Figure 10), when life cycle earnings growth is more fully realized, the second (already smaller) hump disappears. The first hump remains throughout the life cycle. The first group of individuals has low labor market earnings, low savings, and a tight borrowing limits. They also have high discount rates. These individuals want consumption upfront (even with flat income profiles) but cannot access it due to their low borrowing limit. ${ }^{44}$

\footnotetext{
${ }^{44}$ Consider a special case where there is no income growth $\left(y_{1}=y_{2}\right)$ and there is no borrowing constraint. The Euler equation for optimal consumption choices indicates that the optimal consumption in periods 1 and $2, c_{1}^{*}$ and $c_{2}^{*}$, respectively, obey: $\gamma\left(\log c_{2}^{*}-\log c_{1}^{*}\right)=-\rho\left(\theta_{c}, \theta_{n}\right)+\log (1+r)$. Therefore, the following must be true when there is no borrowing constraint: $-\rho\left(\theta_{c}, \theta_{n}\right)+\log (1+r)<0 \Rightarrow c_{2}^{*}<c_{1}^{*}$. Thus, when the discount rate is relatively high (i.e., the agent is less patient), the agent will try to consume more today and consume less tomorrow even if there is no income growth between these two periods $\left(y_{1}=y_{2}\right)$. As a
} 
There is evidence of bimodality in constraints with respect to cognitive and non-cognitive ability in the late 20 s and early 30 s. The patterns with respect to net worth show a sharp cliff. Beyond a certain level, agents are not constrained.

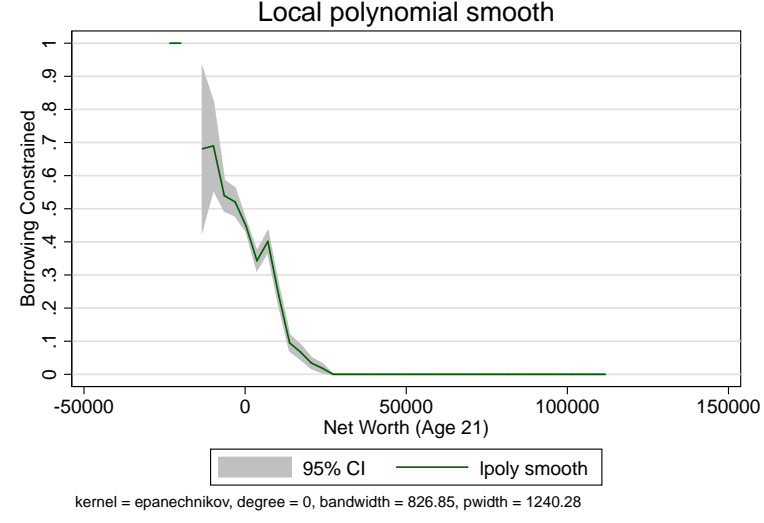

(a) Fraction Constrained vs $s_{t}$

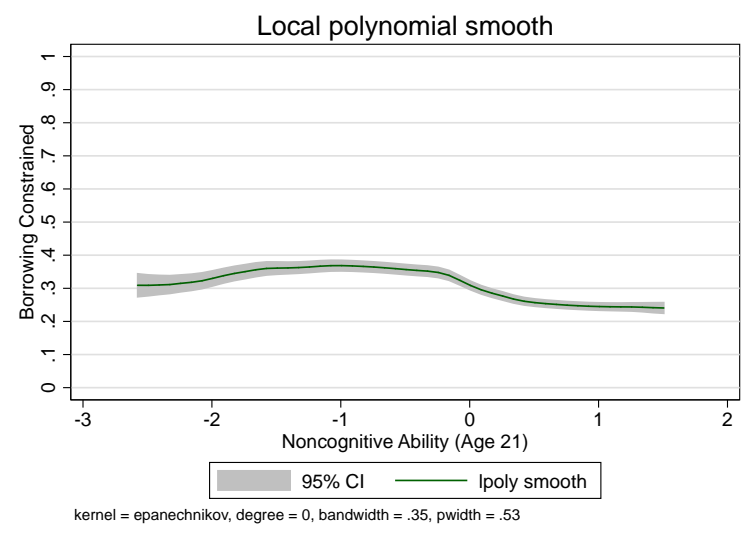

(c) Fraction Constrained vs $\theta_{n}$

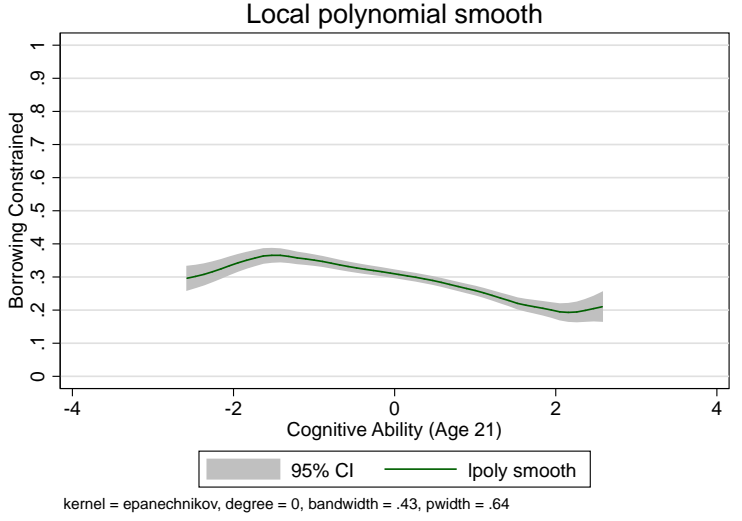

(b) Fraction Constrained vs $\theta_{c}$

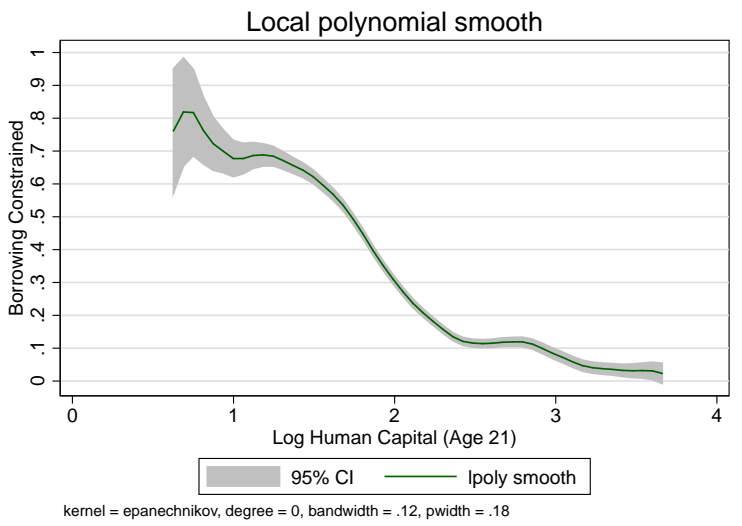

(d) Fraction Constrained $v s \log F^{\psi}\left(e_{t}, k_{t}, \boldsymbol{\theta}, \epsilon_{w, t}\right)$

Figure 8: Borrowing Constrained Youths $\left(s_{t+1} \leq-\bar{L}_{t}^{s}\left(e_{t+1}, k_{t+1}, \boldsymbol{\theta}\right) \& \lambda_{s, t}>0\right)$ at Age 21

Figure 11 shows the life cycle pattern of the proportion borrowing constrained. The $\mathrm{U}$ shape is a consequence of initial borrowing constraints and the approach of the terminal horizon. ${ }^{45}$ The constrained in college are $20 \%$ more likely to work than other college students.

result, the agent will borrow today to consume more today, and pay back the debt in the next period using $y_{2}$ and consume less the next period.

These forces are at work when the agent cannot borrow or cannot borrow enough to reach the optimal consumption level $\left(c_{1}^{*}, c_{2}^{*}\right)$. Low ability individuals with low income growth are borrowing constrained because they are impatient and their borrowing limit is low.

${ }^{45}$ The age 50 horizon artificially accelerates the borrowing constraint into middle age. 


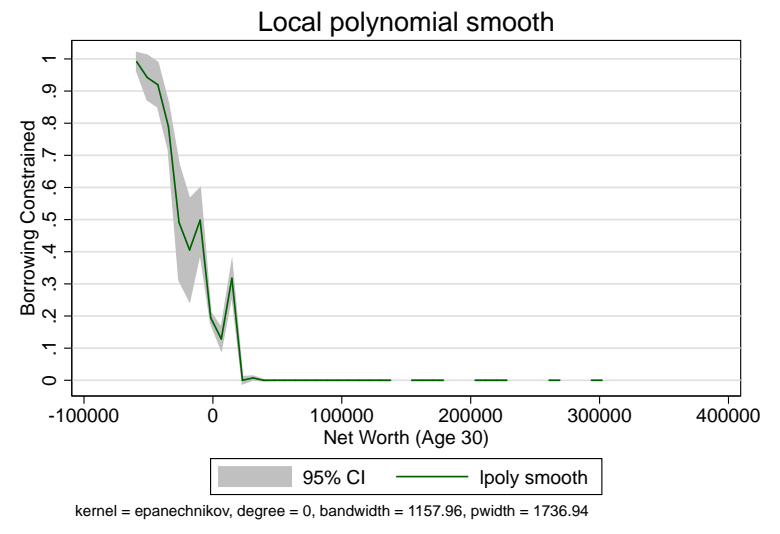

(a) Fraction Constrained vs $s_{t}$

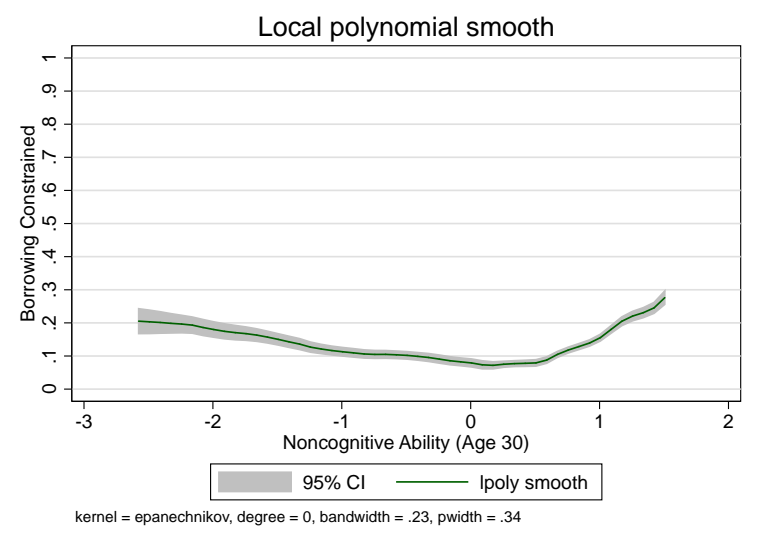

(c) Fraction Constrained vs $\theta_{n}$

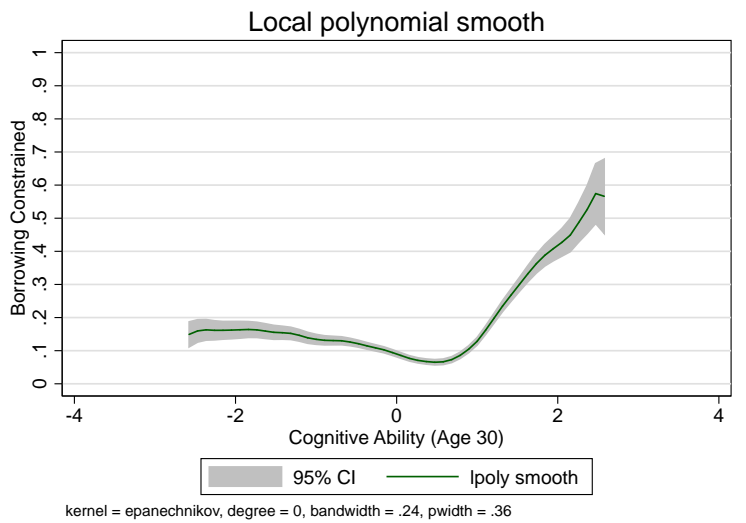

(b) Fraction Constrained vs $\theta_{c}$

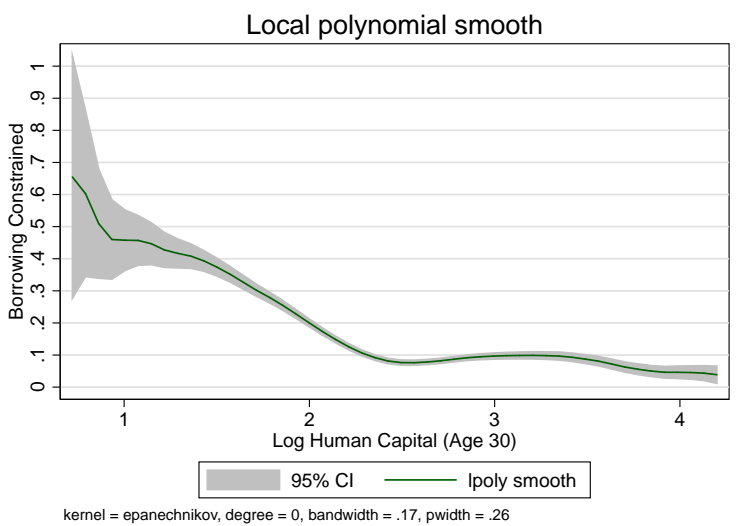

(d) Fraction Constrained $v s \log F^{\psi}\left(e_{t}, k_{t}, \boldsymbol{\theta}, \epsilon_{w, t}\right)$

Figure 9: Borrowing Constrained Youths $\left(s_{t+1} \leq-\bar{L}_{t}^{s}\left(e_{t+1}, k_{t+1}, \boldsymbol{\theta}\right) \& \lambda_{s, t}>0\right)$ at Age 30 


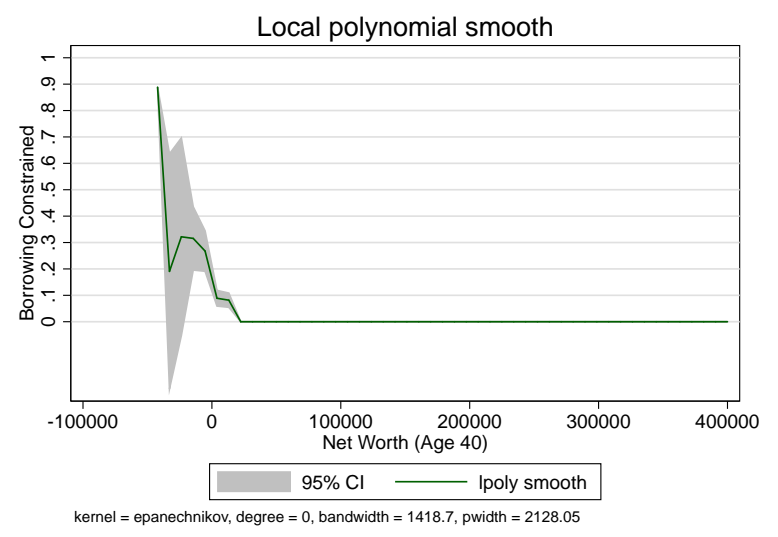

(a) Fraction Constrained $v s s_{t}$

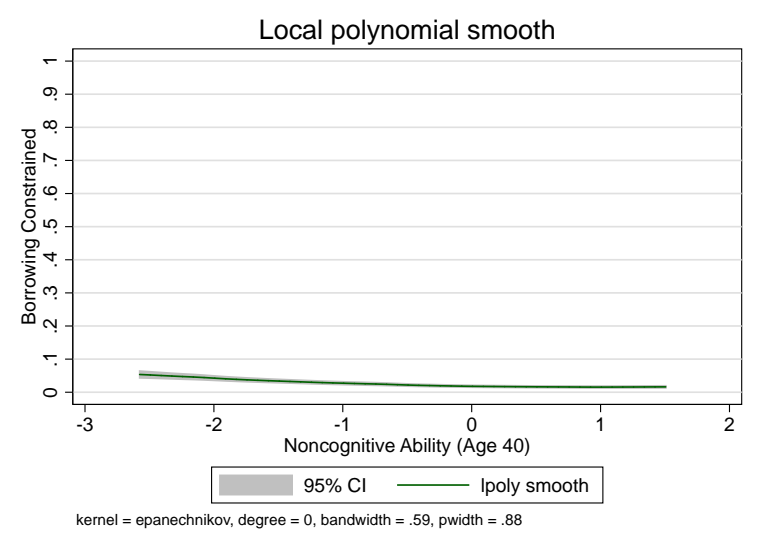

(c) Fraction Constrained vs $\theta_{n}$

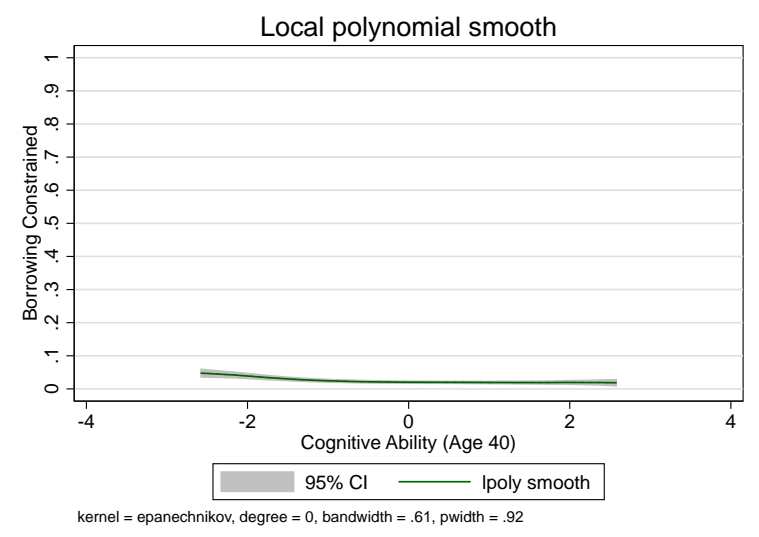

(b) Fraction Constrained vs $\theta_{c}$

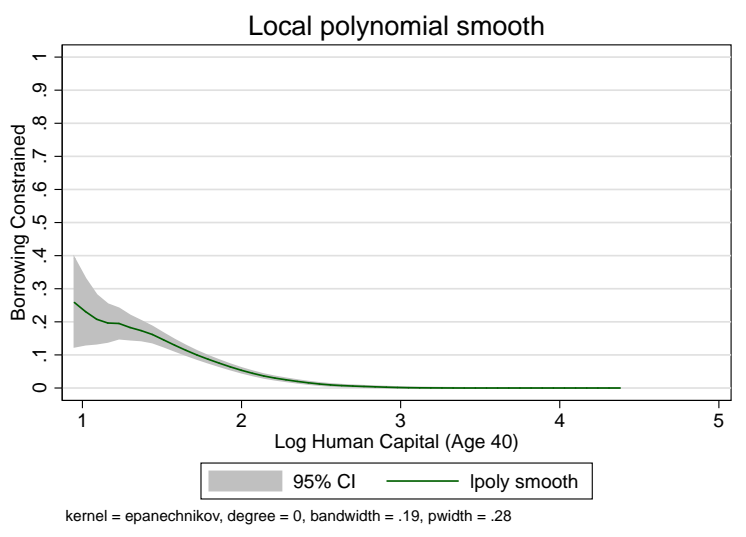

(d) Fraction Constrained $v s \log F^{\psi}\left(e_{t}, k_{t}, \boldsymbol{\theta}, \epsilon_{w, t}\right)$

Figure 10: Borrowing Constrained Youths $\left(s_{t+1} \leq-\bar{L}_{t}^{s}\left(e_{t+1}, k_{t+1}, \boldsymbol{\theta}\right) \& \lambda_{s, t}>0\right)$ at Age 40

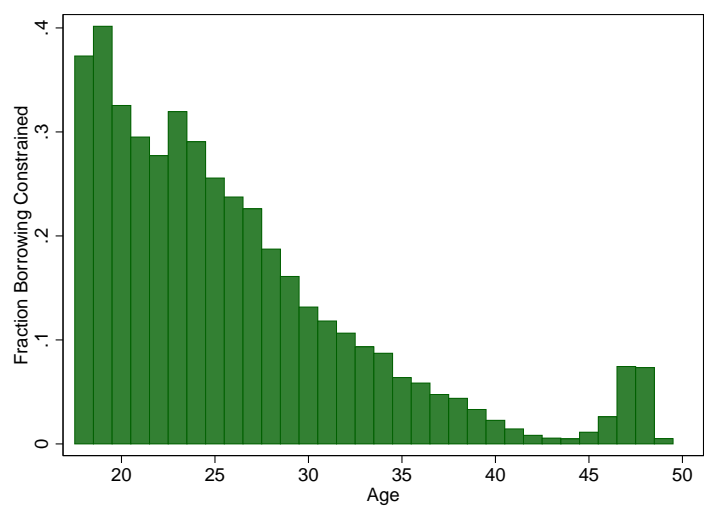

Figure 11: \% Borrowing Constrained by Age 


\subsection{Sorting into Education by Ability}

Simulating our model, we illustrate the magnitude of sorting into education at age 30 based on unobserved abilities. Figure 12 is the density plot of the two unobservabled factors by education groups in the simulated data.

As seen in Figure 12, people sort into education based on cognitive and noncognitive ability. On average, individuals who obtain higher education are more likely to have greater cognitive ability and noncognitive ability. However, there is also substantial overlap in both cognitive ability and noncognitive ability levels across different schooling levels, suggesting that sorting based on abilities is not the only factor shaping individual educational outcomes.
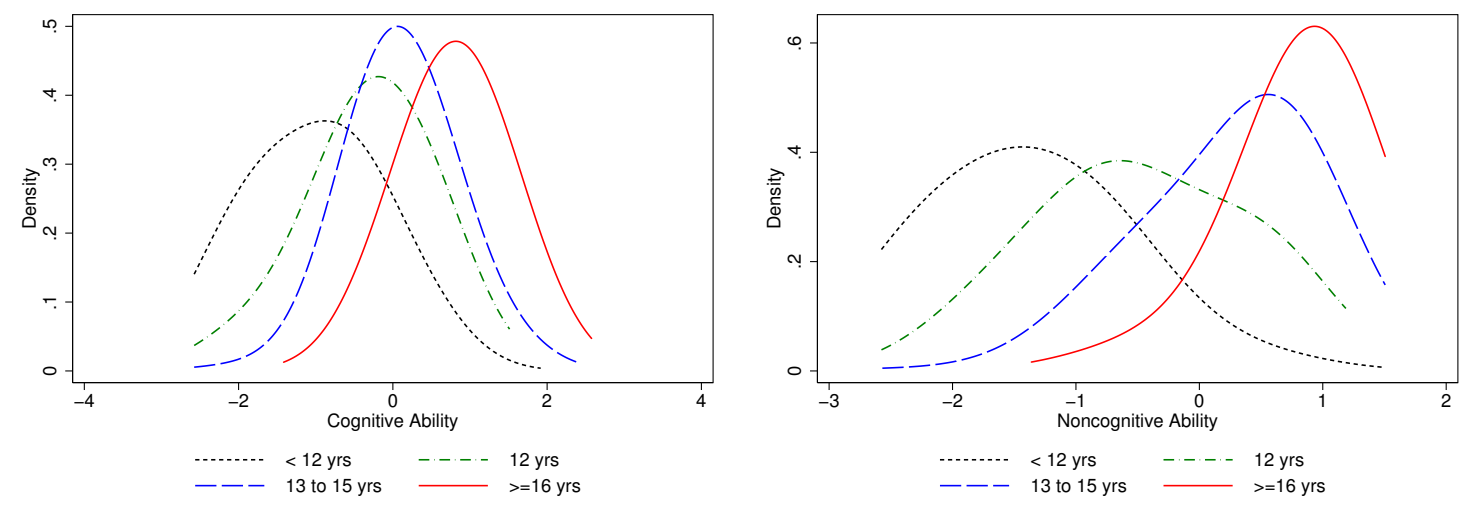

Figure 12: Density of Initial Factors Conditional on Age-30 Education

\subsection{Inequality in Education, Wages, and Consumption}

Both employment decisions and borrowing constraints have important consequences for wage and consumption inequality. ${ }^{46}$ The first row of Table 7 shows the age-30 inequality in education, wages, and consumption in our benchmark model. Cross-sectional inequality is measured by the variance of logs. Wage inequality is higher than education inequality because of the existence of uninsured human capital risk, and large variation in individuals' work experience, cognitive ability, and noncognitive ability. Consumption inequality is lower than

\footnotetext{
${ }^{46}$ The model simulated consumption should be interpreted as all consumption expenditure including rental equivalent consumption values for homeowners and rents for non-homeowners.
} 
wage earning inequality because individuals use savings to smooth consumption fluctuations. We discuss the other rows of this table in the next section when we discuss counterfactuals.

Table 7: Inequality in Education, Wages, and Consumption (Age 30)

\begin{tabular}{|c|c|c|c|c|c|c|}
\hline & \multicolumn{3}{|c|}{ Inequality (Var of log) } & \multicolumn{3}{|c|}{ Changes in Inequality (\%) } \\
\hline & Educ & Wage & $\mathrm{C}$ & Educ & Wage & $\mathrm{C}$ \\
\hline \multirow[t]{2}{*}{ Benchmark } & 0.0395 & 0.3313 & 0.1002 & N.A. & N.A. & N.A. \\
\hline & \multicolumn{6}{|c|}{ Counterfactual Experiments } \\
\hline Equalizing Cognitive Ability & 0.0255 & 0.2924 & 0.0714 & -35.53 & -11.75 & -28.73 \\
\hline Equalizing Noncognitive Ability & 0.0222 & 0.3012 & 0.0775 & -43.88 & -9.08 & -22.69 \\
\hline Equalizing Parental Factors & 0.0363 & 0.3292 & 0.0963 & -8.14 & -0.64 & -3.92 \\
\hline
\end{tabular}

Note: Inequality in education (Educ), wage, and consumption (C) are measured using variance of log years of schooling, log hourly wage rates, and $\log$ consumption at age 30 , respectively. Changes in inequality is calculated as the percentage changes in inequality compared to the benchmark model. When equalizing cognitive ability, we set every individual's cognitive ability equal to the population mean, i.e., zero. Similarly, we set every individual's noncognitive ability equal to zero when equalizing noncognitive ability. When equalizing parental factors, we set parents' education equal to 12 years of schooling and parent's net worth to be in the second tercile. Once cognitive ability, noncognitive ability, and parental factors are all equalized, the variance remains are: $\operatorname{Var}(\log ($ Educ $))=0.0055, \operatorname{Var}(\log ($ Wage $))=0.2623$, and $\operatorname{Var}(\log (\mathrm{C}))$ $=0.0432$.

\section{Counterfactual Exercises}

In this section of the paper, we use our model to examine the impacts of changing credit constraints, tuition, and initial endowments on inequality. We start by analyzing the impact of equalizing endowments.

\subsection{Equalizing Initial Endowments}

We address the following question: To what extent do differences in cognitive ability, noncognitive ability, and parental environments account for the observed cross-section inequality in years of schooling, earnings, and consumption at age 30? To address this question, we perform three counterfactual experiments that equalize initial heterogeneity in (i) cognitive ability, (ii) noncognitive ability, and (iii) parental background factors (including both 
schooling and net worth). Equalization is achieved by placing all observations at the means of the selected variable, keeping other variables at sample values.

As shown in Table 7, equalizing cognitive ability reduces age-30 inequality in education by 36\%. Equalizing noncognitive ability reduces age-30 education inequality by $44 \%$. Finally, equalizing parental factors (including parent's education and net worth) reduces inequality by $8 \%$. Equalizing cognitive endowments reduces wage inequality by $12 \%$ and consumption inequality by $29 \%$. Equalizing noncognitive endowments reduces wage inequality by $9 \%$ and consumption inequality by $23 \%$. Equalizing parental factors has little impact on wage inequality, and it reduces consumption inequality by $4 \%$.

We also investigate the effects of cognitive ability, noncognitive ability and parental factors on the youths' age-17 present discounted lifetime utility inequality. Equalizing cognitive ability reduces age-17 present discounted lifetime utility inequality by $24 \%$. Equalizing noncognitive ability reduces age-17 present discounted lifetime utility inequality by $91 \%$. Equalizing parental factors (including parent's education and net worth) reduces age-17 present discounted lifetime utility inequality by $2 \%$. The age-17 present discounted lifetime utility inequality equal to zero once cognitive ability, noncognitive ability, and parental factors are all equalized.

Table 8: Years of Schooling and College Attendance and Graduation under Different Experiments

\begin{tabular}{lcccc}
\hline \hline & $\begin{array}{c}\text { Years of } \\
\text { Schooling at } \\
\text { Age 30 }\end{array}$ & $\begin{array}{c}\text { College } \\
\text { Attendance at } \\
\text { Age 21 (\%) }\end{array}$ & $\begin{array}{c}\text { 4-Year College } \\
\text { Graduation at } \\
\text { Age 25 (\%) }\end{array}$ & $\begin{array}{c}\text { \% Students } \\
\text { who Work } \\
\text { Part-Time }\end{array}$ \\
\hline Benchmark & 13.76 & 47.25 & 27.76 & 63.45 \\
& & & \\
Counterfactual Experiments & & Changes Relative to Benchmark & \\
\hline (1) Subsidizing College Tuition & 0.18 & 6.22 & 3.55 & -5.72 \\
(2) Increasing Student Loan Limits & 0.04 & 3.95 & 1.09 & 1.28 \\
\hline \hline
\end{tabular}

Note: Education is measured by the average years of schooling at age 30. College attendance is measured as the percentage of individuals whose years of education is more than or equal to 13 at age 21 . The rate of 4 -year college graduation is measured as the percentage of individuals whose years of schooling is more than or equal to 16 at age 25 . The fraction of students who work part-time while in school are calculated over age 18 to 22 . 


\subsection{Subsidizing College Tuition}

We next consider the impact of subsidizing tuition on schooling choices. We give each agent a college tuition subsidy of $\$ 1,500$ per year, which amounts to $29 \%$ of average college tuition cost and fees minus grants and scholarship. ${ }^{47}$ As shown in Table 8, compared to the benchmark model, the college attendance rate at age 21 increases by 6.22 percentage points $(13.17 \%)$. The implied elasticity of college going with respect to tuition is -0.45 , which is within the range of estimates reported in the literature. ${ }^{48}$ This tuition subsidy policy also leads to 3.55 percentage point increase in the 4-year college graduation rate at age 25. The college tuition subsidy reduces students' incentive to work while in school. In particular, under this policy, the fraction of students who work part-time at school decreases by 6 percentage points.

Figure 13 plots the college attendance and the 4-year college graduation rates for the benchmark and tuition subsidy policy over the full distribution of cognitive ability and noncognitive ability. Our college tuition subsidy increases college attendance at age 21 among the individuals whose cognitive ability is within the second and third quartiles. The rate of 4-year college graduation increases much more among high ability individuals compared to that among low ability individuals.

\subsection{Increasing Student Loan Limits}

We next consider the impact of increasing student loan limits. In this counterfactual experiment, we increase the borrowing limit from the student program by $\$ 1,500$ for each academic year, which amounts to a $29 \%$ reduction of average college tuition costs and fees minus grants and scholarship. As shown in Table 8, compared to the benchmark model, the college attendance rate at age 21 increases by 4.0 percentage points and the 4-year college graduation rate at age 25 barely increases. Under the student loan enhancement policy,

\footnotetext{
${ }^{47}$ In the simulation, we do not allow the amount of student loan that an individual can borrow if he decides to attend college to be directly affected by such college tuition subsidy.

${ }^{48}$ See, e.g., Cameron and Heckman (2001) and Heckman and Cameron (1999).
} 


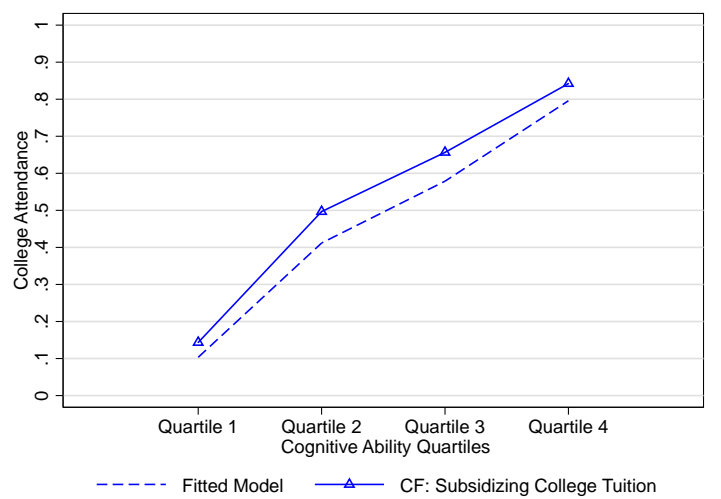

(a) College Attendance \& Cognitive Ability (Age (b) College Attendance \& Noncognitive Ability 21)

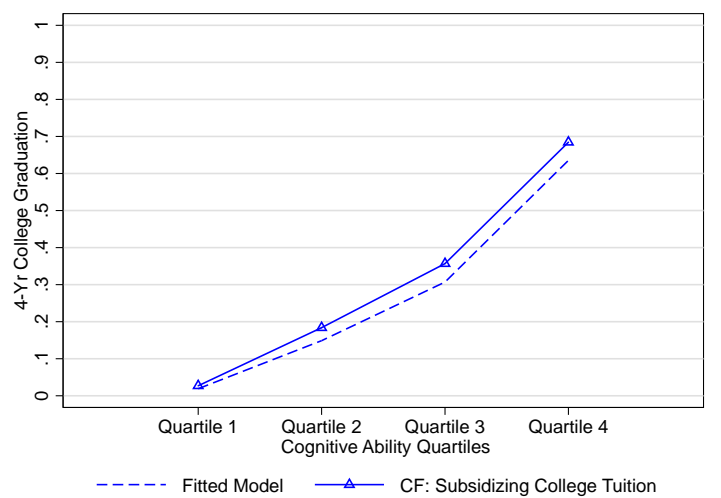

(c) 4-Year College \& Cognitive Ability (Age 25)

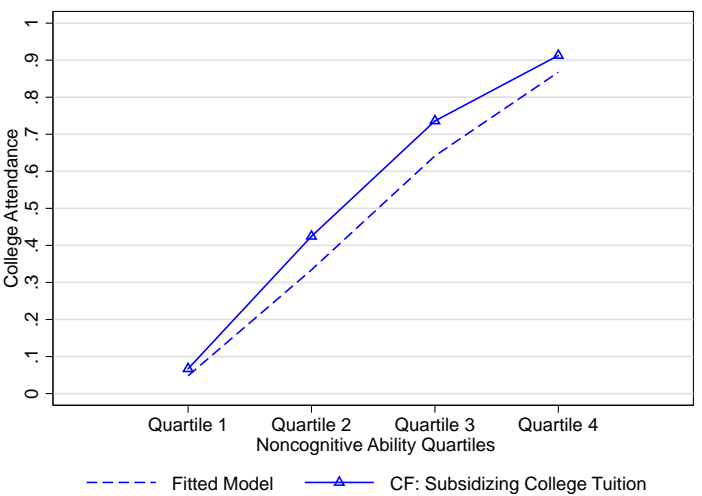
(Age 21)

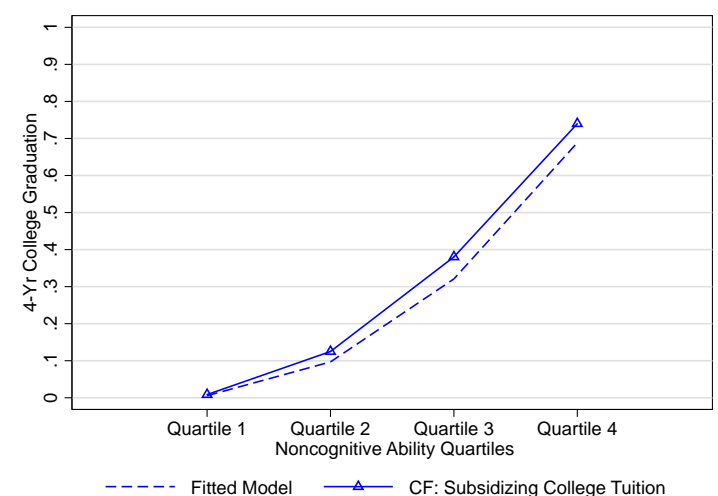

(d) 4-Year College \& Noncognitive Ability (Age 25)

Figure 13: Effects of College Tuition Subsidy

the fraction of students who work part-time in school increases in response to the increased student debt limits. However such increases are small (1 percentage point).

Figure 14 plots the college attendance and the 4-year college graduation rates for the benchmark and enhanced student loan limit policy over the full distribution of cognitive ability and noncognitive ability. The differences are small. ${ }^{49}$ There appears to be a limited role for policies enhancing student access to credit for promoting college attendance and graduation.

\footnotetext{
${ }^{49}$ These results are comparable to those reported in Johnson (2013).
} 

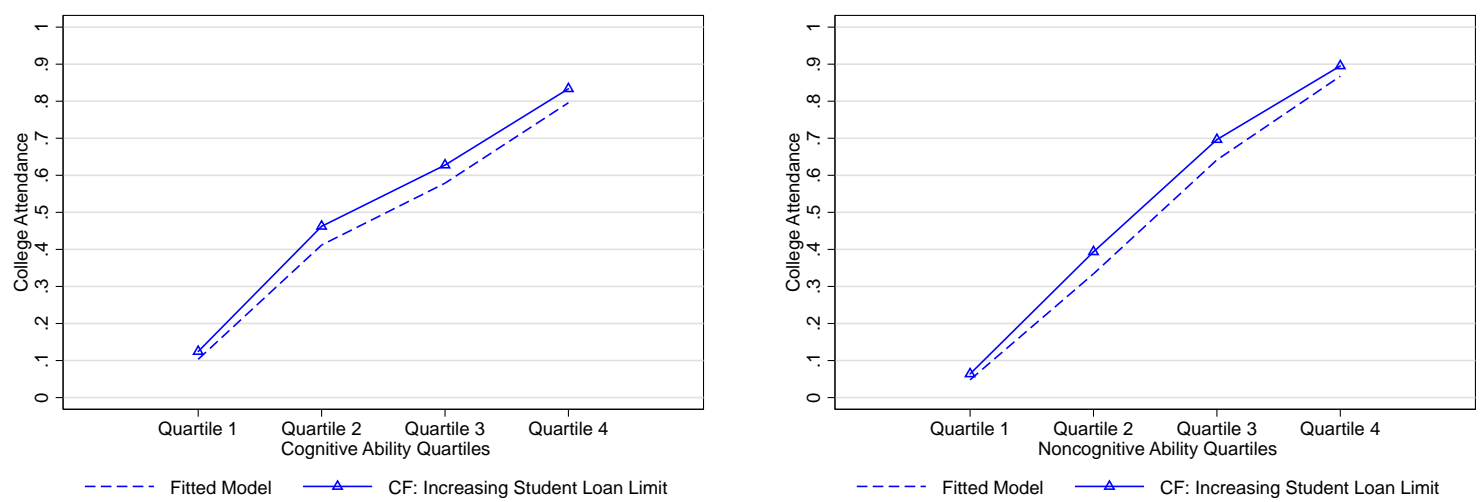

(a) College Attendance \& Cognitive Ability (Age (b) College Attendance \& Noncognitive Ability 21)
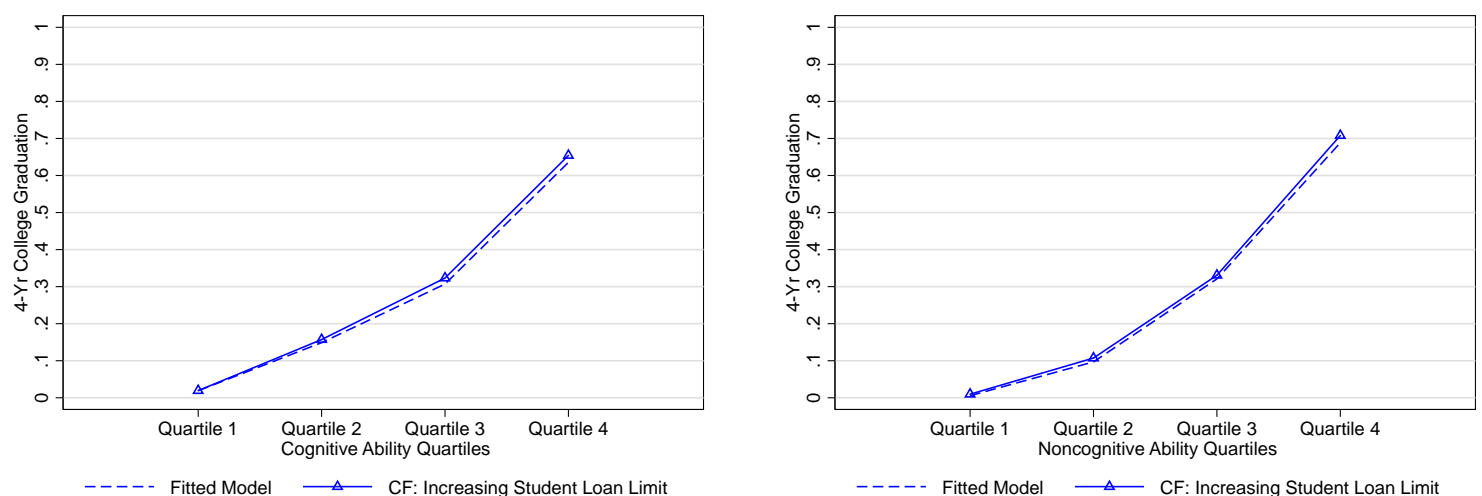

(c) 4-Year College \& Cognitive Ability (Age 25)

(d) 4-Year College \& Noncognitive Ability (Age 25)

Figure 14: Effects of Increasing Student Loan Limits

\section{Comparison with an Alternative Model with Fixed Credit Limits by Educa- tion}

In this section, we estimate a version of our model where borrowing limits are fixed to sample means by education levels. We use the specific constraints analyzed in a recent paper by Abbott et al. (2016). We compare the results obtained under their ad hoc constraint used in that paper and those obtained under our model.

Our model provides a micro-foundation for the underlying borrowing environment, whereas models with ad hoc lending limits do not. The principle advantage of ad hoc models is their computational tractability. It is interesting to compare the quantitative differences in terms 
of parameter estimates, model fits, model predictions, and counterfactual implications.

We follow Abbott et al. (2016) and consider the following specification of credit limits: ${ }^{50}$

$$
\bar{L}_{t}^{s}(e)= \begin{cases}\$ 75,000 & \text { if } e \geq 16 \\ \$ 25,000 & \text { if } e<16 \& e \geq 12 \\ \$ 15,000 & \text { if } e<12\end{cases}
$$

if $t \geq 22$ and $\bar{L}_{t}^{s}(e)=0$ if $t<22$. They justify these limits using averages of self-reported credit limits in the survey of consumer finances.

We apply the same estimation procedure (see Section 5) to estimate this alternative model and estimate the same set of structural parameters. Our model with endogenous debt limit is a far more stringent approach to estimation than models with ad hoc credit limits.

\subsection{Estimation Results}

The last two columns of Web Appendix Table A8 report preference parameter estimates for the schooling utility functions (Panel A) and work utility function (Panel B) in the alternative model. Similar to our model with endogenous credit constraints, we find that he psychic benefit of schooling is higher for individuals with higher cognitive and noncognitive abilities, and is higher if their parents have higher education. We also find that the psychic cost of working part-time while in school $\left(\phi_{k, e}=-0.0603\right)$ is higher than the psychic cost of part-time working while not in school $\left(\phi_{k, 0}=-0.0338\right)$. These estimates are similar in magnitude to those estimated for our model with endogenous credit constraints.

One of the biggest differences in the estimated parameter values between our model and the alternative model lies in the estimated parameter values for the subjective discount rate. In particular, in the alternative model, the estimated discount factor is much higher, which

\footnotetext{
${ }^{50}$ In Abbott et al. (2016), among working-age married households, borrowing limit equals to $\$ 75,000$ if the most educated spouse is a college graduate, $\$ 25,000$ if the most educated spouse is a high school graduate, and $\$ 15,000$ if both spouses are high school dropouts; No borrowing before age 21. Borrowing limits based on self-reported limits on unsecured credit by family type from SCF.
} 
implies that individuals are more patient (see Table A9 to compare parameter estimates). Figure 15 plots the distribution of estimated discount factors. Appendix Figure 4(c) plots the density of estimated discount factor for high cognitive ability and low cognitive ability. Appendix Figure 4(d) plots the density of estimated discount factor for high cognitive noncognitive ability and low noncognitive ability. As in our model, those with higher cognitive and/or noncognitive skills have lower rates of time preference.

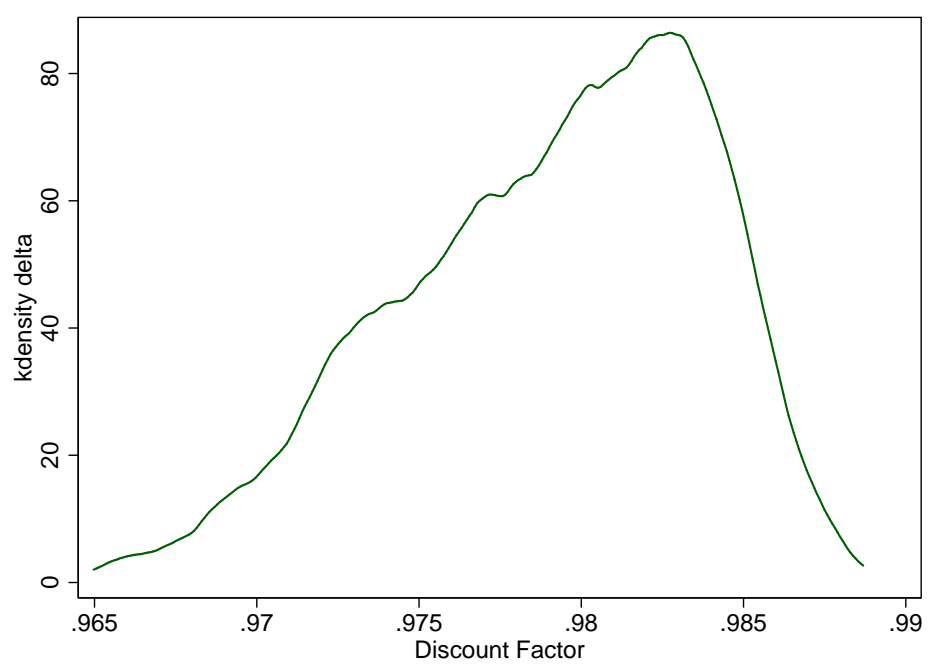

Figure 15: Density of Estimated Discount Factors (Fixed Credit Limits by Education): $\exp \left(-\rho\left(\theta_{c}, \theta_{n}\right)\right)$

This has important implications for the estimated levels of human and physical capital accumulation. The overall fit of this model to the data is worse than our model. The minimized SMM objective function in this model is $76 \%$ larger than in our model with endogenous credit constraints. The fit of the model to the data is worse for many components of life cycle behavior than our model (for example, compare Figures 16 and 17 with Figures 4 and 5, and appendix Table A14). Sorting patterns into education by ability are similar (see Figure 18). 


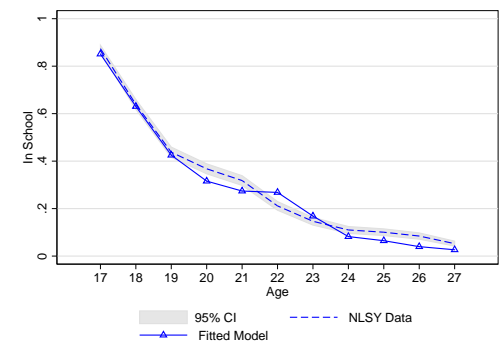

(a) In School

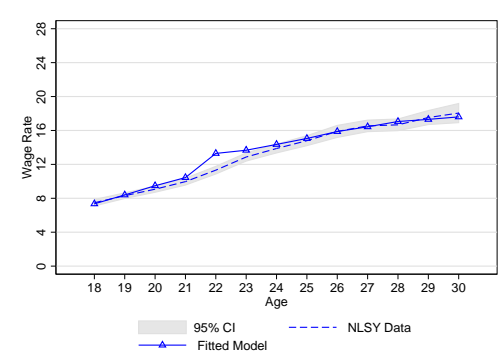

(d) Hourly Wages over Age

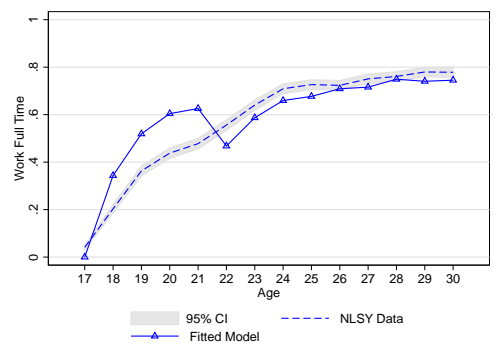

(b) Working Full-time

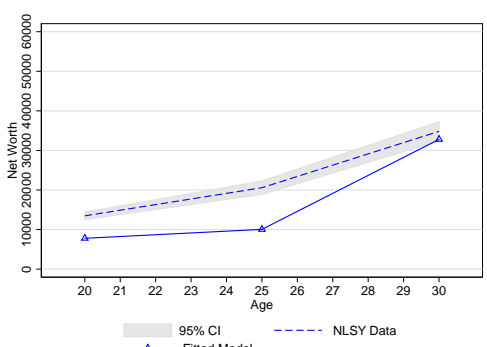

(e) Net Worth by Age

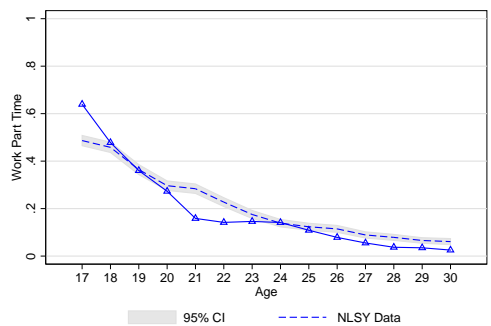

$95 \% \mathrm{Cl}$
$\triangle \quad$ Fitted Mo

(c) Working Part-time

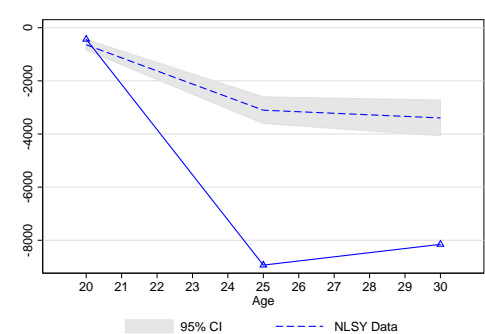

(f) Negative Net Worth by Age

Figure 16: Goodness of Fit over the Lifecycle (Alternative Model)

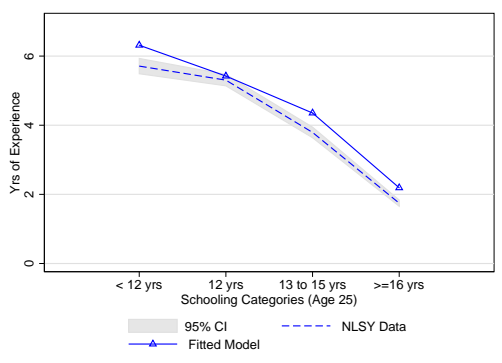

(a) Yrs Worked by Education

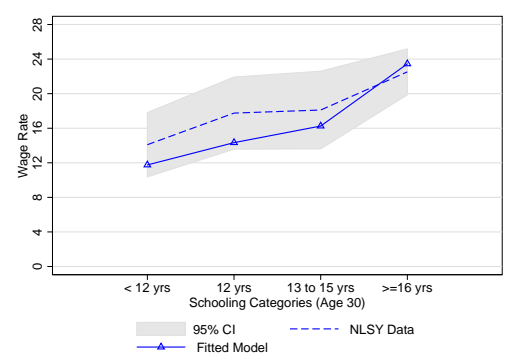

(b) Hourly Wages by Education

Figure 17: Goodness of Fit by Education (Alternative Model)

Similar to our analysis of the model with endogenous credit constraints, we also report the evolution of credit limit for the Abbott et al. model. In the ad hoc model, the credit limit does not change with age or work experience after the agent completes the highest degree (see Web Appendix Figure A10(a)). Conditional on age, the credit limit is bounded below at $\$ 15,000$ and increases with human capital, which is due to the fact on average higher educated individuals have higher human capital level (Web Appendix Figure A10(b)). At age 30 , the borrowing limit increases with education, cognitive ability, and noncognitive 

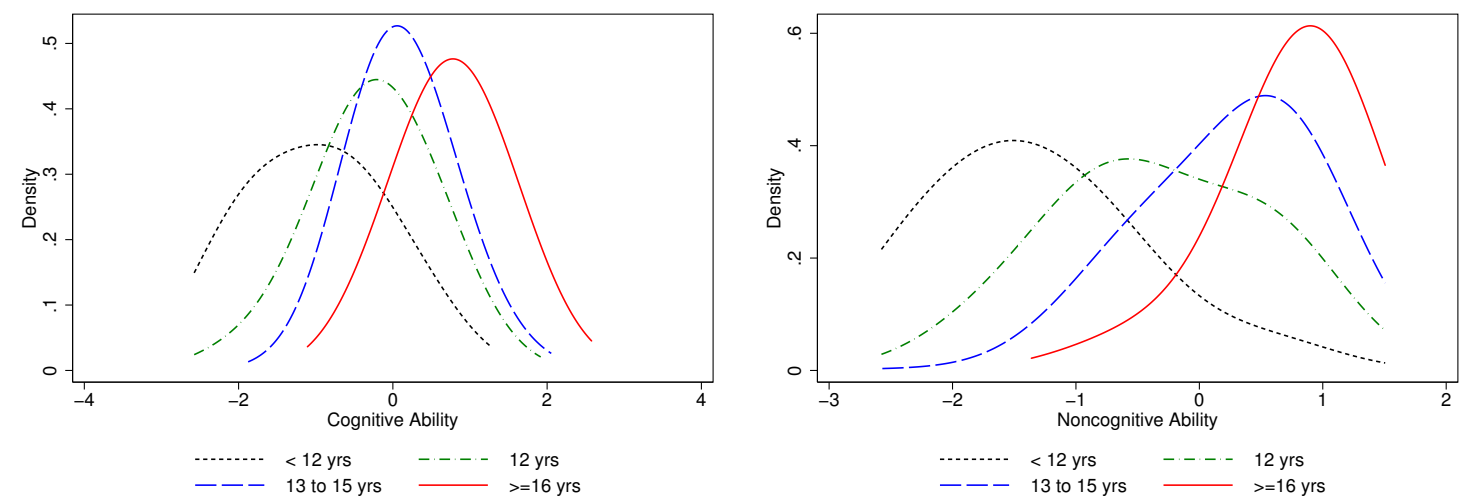

Figure 18: Density of Initial Factors Conditional on Age-30 Education (Alternative Model)

ability; but there is no heterogeneity in credit limits within each education category (see Web Appendix Figure A15).

The estimated patterns of constraints by age and individual characteristics are different across the two models. The age 21 patterns are roughly similar, but the hump is more noticeable in the ad hoc model. The weak bimodality at age 30 found in our model is not present in the ad hoc model, and the proportion of agents constrained is much lower. The fraction of borrowing constrained population continues to decrease and reaches zero after age 45 (Figure 19). ${ }^{51}$

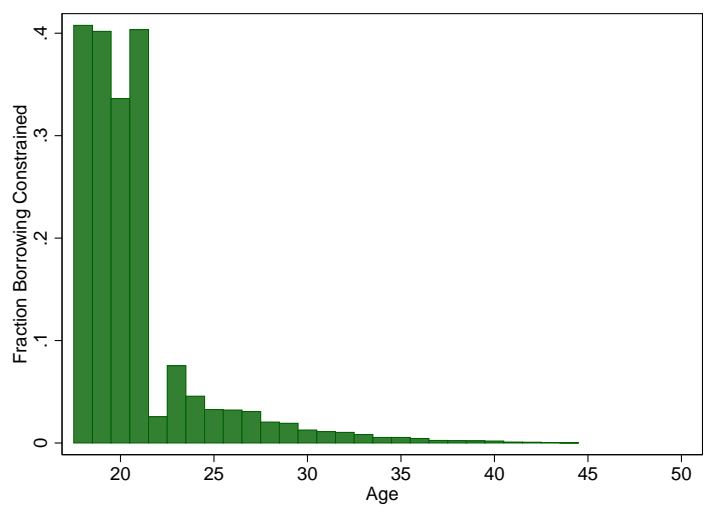

Figure 19: \% Borrowing Constrained by Age for Alternative Model

\footnotetext{
${ }^{51}$ After college is completed, the private debt limit in the ad hoc model is set at a very large number.
} 


\subsection{Counterfactual Experiments}

Differences are sharp between the two models when we consider the same set of policy experiments conducted for our model with endogenous credit constraints. We consider the implications of changing endowments, tuition and credit limits in the ad hoc model for the same set of policies considered in the discussion of the endogenous credit constrained model. We start by equalizing initial endowments.

\subsubsection{Equalizing Initial Endowments}

As shown in Table 9, equalizing cognitive ability reduces age-30 inequality in education by $36 \%$ (about the same as in the model with endogenous constraints). Equalizing noncognitive ability reduces age-30 education inequality by $38 \%$ - less than in our model (44\%). Finally, equalizing parental factors (including parent's education and net worth) reduces inequality by $6 \%$ (compared to $8 \%$ for our model). These equalizing effects are generally smaller than in the model with endogenous credit constraints.

Equalizing cognitive endowments reduces wage inequality by $12 \%$ (about the same as in the model with endogenous constraints) and consumption inequality by $40 \%$ (compared to $29 \%$ for our model). Equalizing noncognitive endowments reduces wage inequality by $9 \%$ (vs 9\%) and consumption inequality by $33 \%$ (vs 23\%). Equalizing parental factors has little impact on wage inequality, and reduces consumption inequality by $5 \%$ (compared to $4 \%$ for our model). 
Table 9: Inequality in Education, Wages, and Consumption at Age 30 (Fixed Credit Limits by Education)

\begin{tabular}{lcccccc}
\hline \hline & \multicolumn{3}{c}{ Inequality $($ Var of $\log )$} & \multicolumn{3}{c}{ Changes in Inequality (\%) } \\
\cline { 2 - 7 } & Educ & Wages & C & Educ & Wages & C \\
\hline Benchmark & 0.0398 & 0.3825 & 0.1168 & N.A. & N.A. & N.A.
\end{tabular}

\begin{tabular}{lcccccc} 
& \multicolumn{5}{c}{ Counterfactual Experiments } \\
\cline { 2 - 7 } Equalizing Cognitive Ability & 0.0253 & 0.3360 & 0.0704 & -36.37 & -12.17 & -39.75 \\
Equalizing Noncognitive Ability & 0.0248 & 0.3471 & 0.0784 & -37.76 & -9.27 & -32.89 \\
Equalizing Parental Factors & 0.0375 & 0.3782 & 0.1112 & -5.75 & -1.14 & -4.83 \\
\hline \hline
\end{tabular}

Note: Inequality in Education (Educ), wages, and consumption (C) are measured using variance of log years of schooling, log hourly wage rates, and log consumption at age 30, respectively. Changes in inequality is calculated as the percentage changes in inequality compared to the benchmark model. When equalizing cognitive ability, we set every individual's cognitive ability equal to the population mean, i.e., zero. Similarly, we set every individual's noncognitive ability equal to zero when equalizing noncognitive ability. When equalizing parental factors, we set parents' education equal to 12 years of schooling and parent's net worth to be in the second tercile.

Table 10: Years of Schooling and College Attendance and Graduation under Different Experiments (Fixed Credit Limits by Education)

\begin{tabular}{lcccc}
\hline \hline & $\begin{array}{c}\text { Years of } \\
\text { Schooling at } \\
\text { Age 30 }\end{array}$ & $\begin{array}{c}\text { College } \\
\text { Attendance at } \\
\text { Age 21 (\%) }\end{array}$ & $\begin{array}{c}\text { 4-Year College } \\
\text { Graduation at } \\
\text { Age 25 (\%) }\end{array}$ & $\begin{array}{c}\text { \% Students } \\
\text { who Work } \\
\text { Part-Time }\end{array}$ \\
\hline Benchmark & 13.52 & 48.44 & 34.53 & 64.83 \\
Counterfactual Experiments & & Changes Relative to Benchmark & \\
\hline (1) Subsidizing College Tuition & 0.29 & 7.63 & 5.78 & -5.11 \\
(2) Increasing Student Loan Limits & 0.12 & 4.60 & 2.34 & 0.60 \\
\hline \hline
\end{tabular}

Note: Education is measured by the average years of schooling at age 30. College attendance is measured as the percentage of individuals whose years of education is more than or equal to 13 at age 21 . The rate of 4 -year college graduation is measured as the percentage of individuals whose years of schooling is more than or equal to 16 at age 25 . The fraction of students who work part-time while in school are calculated over age 18 to 22 .

\subsubsection{Subsidizing College Tuition}

This section reports the effects of a tuition subsidy on schooling choices. We give each agent a college tuition subsidy of $\$ 1,500$ per year, which amounts to $29 \%$ of average college 
tuition cost and fees minus grants and scholarship. ${ }^{52}$ As shown in Table 10, compared to the benchmark model, the college attendance rate at age 21 increases by 7.63 percentage points (15.76\%). The implied elasticity of college going with respect to tuition is -0.54 , which is much higher than the elasticity obtained in the model with endogenous credit limits. Such a tuition subsidy policy also leads to 5.78 percentage points increase in the 4-year college graduation rate at age 25. The fraction of students age 18 to 22 who work part-time at school decreases by 5.1 percentage points.
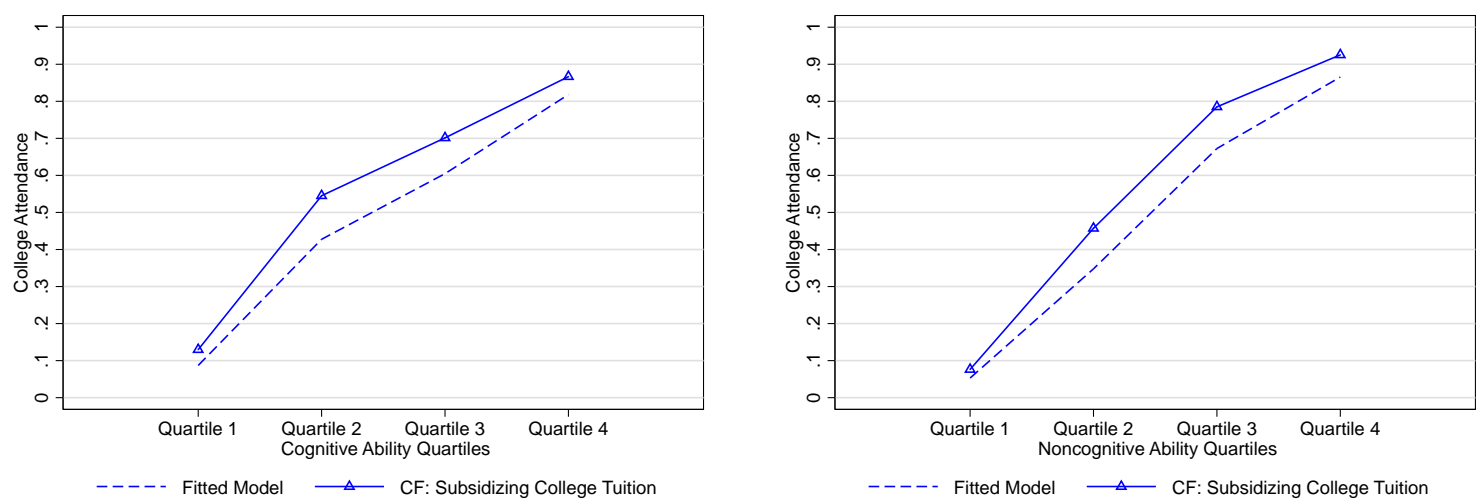

(a) College Attendance \& Cognitive Ability (Age (b) College Attendance \& Noncognitive Ability 21) (Age 21)
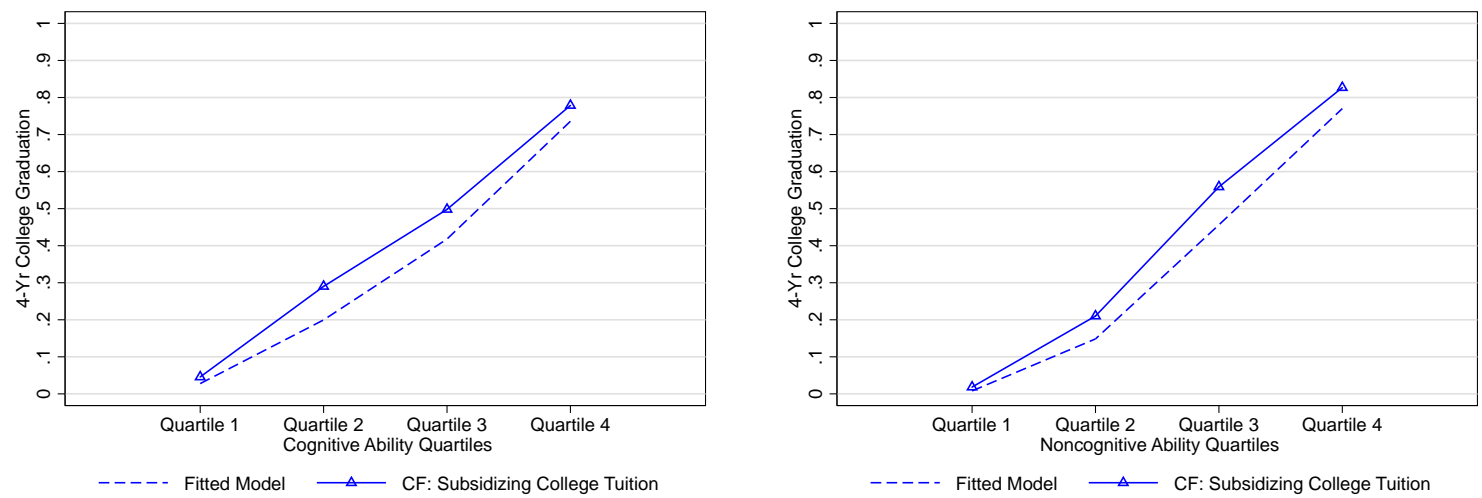

(c) 4-Year College \& Cognitive Ability (Age 25) (d) 4-Year College \& Noncognitive Ability (Age 25)

Figure 20: Effects of College Tuition Subsidy on Attendance and Graduation (Fixed Credit Limits by Education)

\footnotetext{
${ }^{52}$ In the simulation, we do not allow the amount of student loan that an individual can borrow if he decides to attend college to be directly affected by such college tuition subsidy.
} 
Figure 20 plots the college attendance and the 4-year college graduation rates for the benchmark and reduced tuition policy over the full distribution of cognitive ability and noncognitive ability. The college tuition subsidy increases the college attendance at age 21 for all quartiles of cognitive ability, including those located at the lowest cognitive ability quartile.

In summary, the model with education-specific fixed credit limits predicts a higher elasticity of response to tuition than the model with an endogenous borrowing limit. Ad hoc credit limits of the sort used by Abbott et al. (2016) overstate somewhat the effectiveness of a tuition-reduction policy. This finding is intuitive because restricting borrowing limits to be the same within each education group over-predicts the amount of debt a low-ability individual can borrow from private debt market and thus over-predicts the net benefits of college education for low ability students. In our model, even after conditioning on education, our model predicts that the amount of debt an individual can borrow is lower if the individual has lower human capital (either due to low abilities or low work experience) and if the individual has a higher psychic cost of working.

\subsubsection{Increasing Student Loan Limits}

In this counterfactual experiment, we increase the borrowing limit from the student program by $\$ 1,500$ for each academic year (the same as in the analysis of our model). As shown in Table 10, such policy experiments lead to a 4.60 percentage point increase in the college attendance rate at age 21 and 2.34 percentage points increase in the 4-year college graduation rate at age 25 . The fraction of students age 18 to 22 who work part-time while in school increases by 0.6 percentage points. Figure 21 plots the college attendance and the 4-year college graduation rates for the benchmark and enhanced student loan limit policy over the full distribution of cognitive ability and noncognitive ability. The differences are small. ${ }^{53}$ These results are comparable to those obtained from the model with endogenous

\footnotetext{
${ }^{53}$ These results are comparable to those reported in Johnson (2013).
} 
credit constraints.
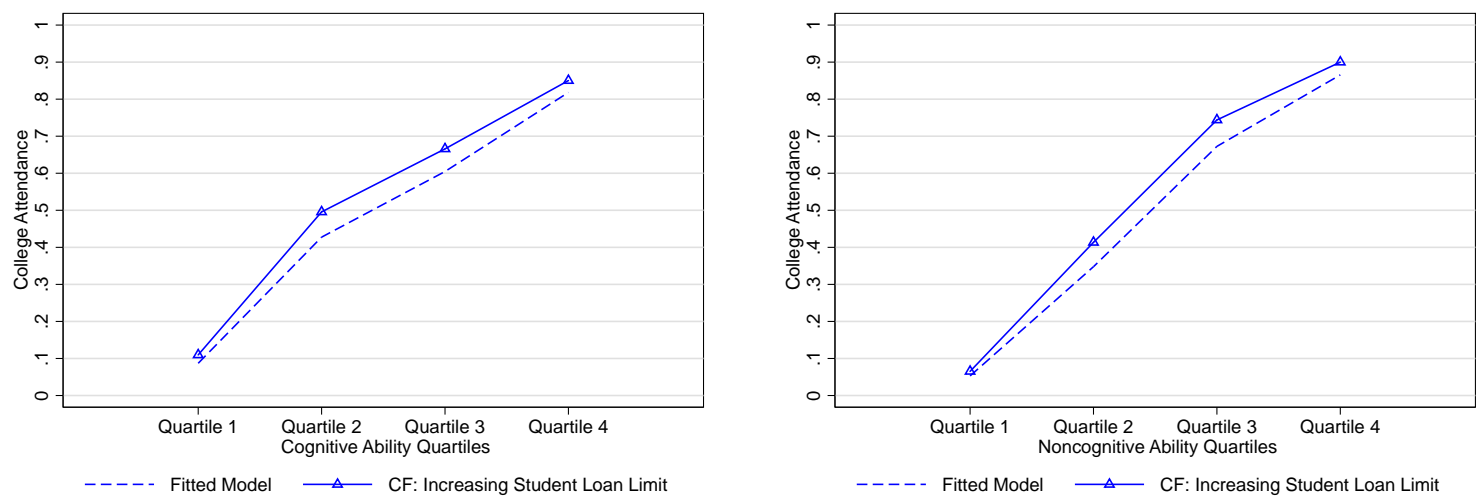

(a) College Attendance \& Cognitive Ability (Age (b) College Attendance \& Noncognitive Ability 21) (Age 21)
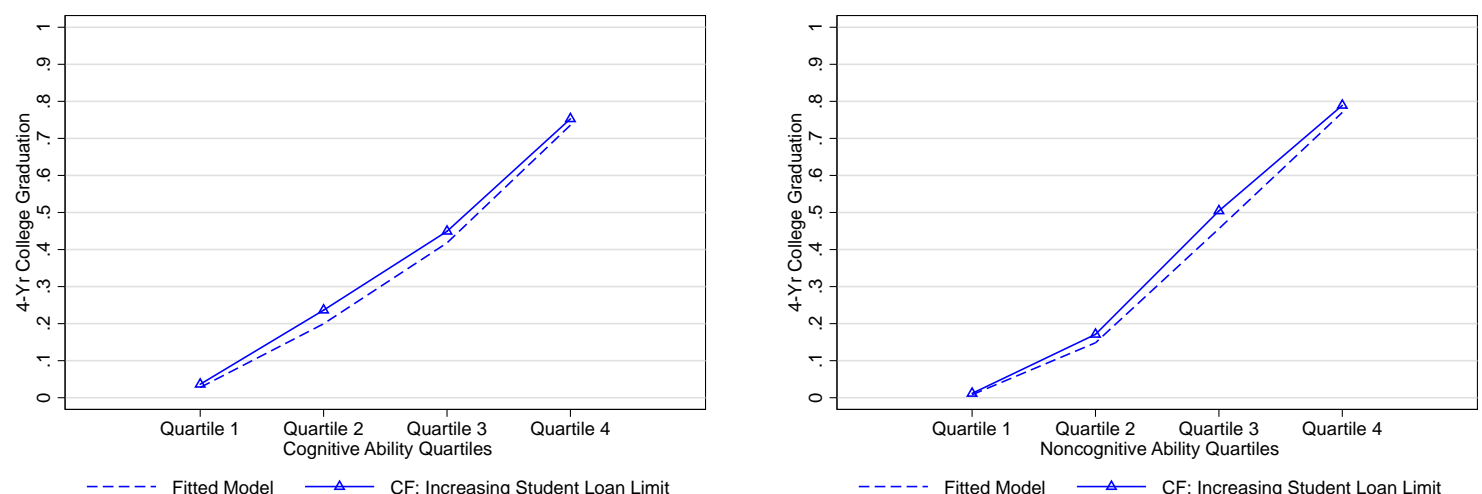

(c) 4-Year College \& Cognitive Ability (Age 25) (d) 4-Year College \& Noncognitive Ability (Age 25)

Figure 21: Effects of Increasing Student Loan Limits on Attendance and Graduation (Fixed Credit Limits by Education) 


\section{Summary and Conclusion}

This paper estimates a life cycle model of human capital and work experience with parental transfers in the presence of endogenous borrowing limits and precautionary savings motives. In our model, individuals are subject to uninsured human capital risks and choose to invest in education, accumulate work experience and assets, and smooth consumption. Borrowing is permitted up to an endogenously determined limit. The limit is explicitly derived. Our model extends Aiyagari's (1994) analysis by considering the effects of labor supply and human capital accumulation on the supply of available credit. We account for the private lending market and government student loan programs. We use our estimated model to investigate the determinants of human capital inequality and to examine the relationship between educational attainment, cognitive and noncognitive abilities, and parental education

and wealth. We analyze the effects of tuition subsidies and enhanced student loan limits on educational attainment and human capital inequality. We do not introduce arbitrary free parameters into our analysis of credit constraints, nor do we impose ad hoc borrowing constraints.

We find substantial evidence of life cycle credit constraints that affect human capital accumulation and inequality. Constrained individuals fall into two groups. A large proportion of the chronically poor with low initial endowments and abilities who acquire little skill over their lifetimes are constrained. There is also a smaller portion of initially well-endowed persons with high levels of acquired skills who are constrained early in their life cycles. The first group has flat life cycle wage profiles. Most remain constrained over their lifetimes. The second group has rising life cycle wage profiles. They are constrained only early on in life because they cannot immediately access their future earnings. As they age, their constraints are relaxed as they access their future earnings.

Equalizing cognitive and noncognitive ability (separately and together) has dramatic effects on reducing inequality in education. Equalizing parental backgrounds has a much weaker effect on inequality in earnings and consumption. Reducing tuition has substantial 
impacts on schooling, but has only minor effects on our measures of inequality (even lifetime utility). Enhancing student loan limits has minor effects on all outcomes studied.

We compare the estimates from our model with those from a recent model that imposes ad hoc credit constraints by education level. There are differences in the predictions across models. The ad hoc approach overstates the likely effectiveness of tuition policy and understates the fraction of individuals who are constrained.

\section{Acknowledgements}

We thank Dean Corbae, Mariacristina De Nardi, Lance Lochner, Steve Stern, and participants at the Human Capital and Inequality Conference held at Chicago on December 17th, 2015, for helpful comments and suggestions on an earlier draft of this paper. We also thank Joseph Altonji, Peter Arcidiacono, Panle Jia Barwick, Jeremy Fox, Jorge García, Limor Golan, Lars Hansen, John Kennan, Rasmus Lentz, Maurizio Mazzocco, Aloysius Siow, Ronni Pavan, John Rust, Bertel Schjerning, Christopher Taber, and participants at the Cowles Conference in Structural Microeconomics and the Stanford Institute for Theoretical Economics (SITE) Summer Workshop for helpful comments. We also thank two anonymous referees. Yu Kyung Koh provided very helpful comments on this paper. This research was supported in part by: the Pritzker Children's Initiative; the Buffett Early Childhood Fund; NIH grants NICHD R37HD065072, NICHD R01HD054702, and NIA R24AG048081; an anonymous funder; Successful Pathways from School to Work, an initiative of the University of Chicago's Committee on Education and funded by the Hymen Milgrom Supporting Organization; the Human Capital and Economic Opportunity Global Working Group, an initiative of the Center for the Economics of Human Development and funded by the Institute for New Economic Thinking; and the American Bar Foundation. The views expressed

in this paper are solely those of the authors and do not necessarily represent those of the funders or the official views of the National Institutes of Health. The Web Appendix for this paper is located at https://cehd.uchicago.edu/human-capital-constraints. 
Abbott, B., Gallipoli, G., Meghir, C., Violante, G. L., March 2016. Education policy and intergenerational transfers in equilibrium, under revision, Journal of Political Economy.

Aiyagari, S. R., August 1994. Uninsured idiosyncratic risk and aggregate saving. Quarterly Journal of Economics 109 (3), 659-684.

Albuquerque, R., Hopenhayn, H. A., 2004. Optimal lending contracts and firm dynamics. Review of Economic Studies 71 (2), 285-315.

Altonji, J. G., Segal, L. M., July 1996. Small-sample bias in GMM estimation of covariance structures. Journal of Business and Economic Statistics 14 (3), 353-366.

Alvarez, F., Jermann, U. J., 2001. Quantitative asset pricing implications of endogenous solvency constraints. Review of Financial Studies 14 (4), 1117-1151.

Anderson, T. W., Rubin, H., 1956. Statistical inference in factor analysis. In: Neyman, J. (Ed.), Proceedings of the Third Berkeley Symposium on Mathematical Statistics and Probability. Vol. 5. University of California Press, Berkeley, CA, pp. 111-150.

Bailey, M. J., Dynarski, S. M., 2011. Inequality in postsecondary education. In: Duncan, G. J., Murnane, R. J. (Eds.), Whither Opportunity? Rising Inequality, Schools, and Children's Life Chances. Russell Sage Foundation, New York, Ch. 6, pp. 117-132.

Belley, P., Lochner, L., December 2007. The changing role of family income and ability in determining educational achievement. Journal of Human Capital 1 (1), 37-89.

Blundell, R., Costa Dias, M., Meghir, C., Shaw, J., September 2016. Female labor supply, human capital, and welfare reform. Econometrica 84 (5), 1705-1753.

Browning, M., Hansen, L. P., Heckman, J. J., 1999. Micro data and general equilibrium models. In: Taylor, J. B., Woodford, M. (Eds.), Handbook of Macroeconomics. Vol. 1A. Elsevier B. V., Amsterdam, Ch. 8, pp. 543-633. 
Cagetti, M., De Nardi, M., October 2006. Entrepreneurship, frictions, and wealth. Journal of Political Economy 114 (5), 835-870.

Cameron, S. V., Heckman, J. J., June 2001. The dynamics of educational attainment for black, Hispanic, and white males. Journal of Political Economy 109 (3), 455-499.

Cameron, S. V., Taber, C., February 2004. Estimation of educational borrowing constraints using returns to schooling. Journal of Political Economy 112 (1), 132-182.

Carneiro, P., Heckman, J. J., October 2002. The evidence on credit constraints in postsecondary schooling. Economic Journal 112 (482), 705-734.

Caucutt, E. M., Lochner, L. J., October 2012. Early and late human capital investments, borrowing constraints, and the family. Working Paper 18493, National Bureau of Economic Research.

Chatterjee, S., Corbae, D., Nakajima, M., Ríos-Rull, J.-V., November 2007. A quantitative theory of unsecured consumer credit with risk of default. Econometrica 75 (6), 1525-1589.

Cooley, T., Marimon, R., Quadrini, V., 2004. Aggregate consequences of limited contract enforceability. Journal of Political Economy 112 (4), 817-847.

Cunha, F., Heckman, J. J., Fall 2008. Formulating, identifying and estimating the technology of cognitive and noncognitive skill formation. Journal of Human Resources 43 (4), 738-782.

Cunha, F., Heckman, J. J., Schennach, S. M., May 2010. Estimating the technology of cognitive and noncognitive skill formation. Econometrica 78 (3), 883-931.

De Nardi, M., 2004. Wealth inequality and intergenerational links. Review of Economic Studies 71 (3), 743-768.

Fernández-Villaverde, J., Krueger, D., August 2007. Consumption over the life cycle: Facts from consumer expenditure survey data. Review of Economics and Statistics 89 (3), $552-$ 565. 
Gertler, M., Kiyotaki, N., 2010. Financial intermediation and credit policy in business cycle analysis. In: Friedman, B. M., Woodford, M. (Eds.), Handbook of Monetary Economics. Vol. 3. Elsevier B. V., Amsterdam, Ch. 11, pp. 547-599.

Gourinchas, P.-O., Parker, J. A., January 2002. Consumption over the life cycle. Econometrica $70(1), 47-89$.

Heckman, J. J., Cameron, S. V., 1999. Can tuition policy combat rising wage inequality? In: Kosters, M. H. (Ed.), Financing College Tuition: Government Policies and Educational Priorities. AEI Press, Washington, DC, pp. 76-124.

Heckman, J. J., Humphries, J. E., Veramendi, G., April 2016. Dynamic treatment effects. Journal of Econometrics 191 (2), 276-292.

Heckman, J. J., Kautz, T., 2014. Fostering and measuring skills: Interventions that improve character and cognition. In: Heckman, J. J., Humphries, J. E., Kautz, T. (Eds.), The Myth of Achievement Tests: The GED and the Role of Character in American Life. University of Chicago Press, Chicago, Ch. 9, pp. 341-430.

Heckman, J. J., Mosso, S., August 2014. The economics of human development and social mobility. Annual Review of Economics 6 (1), 689-733.

Heckman, J. J., Navarro, S., February 2007. Dynamic discrete choice and dynamic treatment effects. Journal of Econometrics 136 (2), 341-396.

Heckman, J. J., Pinto, R., Savelyev, P. A., October 2013. Understanding the mechanisms through which an influential early childhood program boosted adult outcomes. American Economic Review 103 (6), 2052-2086.

Huggett, M., September-November 1993. The risk-free rate in heterogeneous-agent incomplete-insurance economies. Journal of Economic Dynamics and Control 17 (5-6), 953-969. 
Jermann, U. J., Quadrini, V., 2012. Macroeconomic effects of financial shocks. The American Economic Review 102 (1), 238-271.

Johnson, M. T., October 2013. Borrowing constraints, college enrollment, and delayed entry. Journal of Labor Economics 31 (4), 669-725.

Kaplan, G., June 2012. Moving back home: Insurance against labor market risk. Journal of Political Economy 120 (3), 446-512.

Kautz, T., Zanoni, W., 2015. Measuring and fostering non-cognitive skills in adolescence: Evidence from Chicago Public Schools and the OneGoal Program, unpublished manuscript, University of Chicago, Department of Economics.

Keane, M. P., Wolpin, K. I., November 2001. The effect of parental transfers and borrowing constraints on educational attainment. International Economic Review 42 (4), 1051-1103.

Kehoe, T. J., Levine, D. K., 1993. Debt-constrained asset markets. Review of Economic Studies 60 (4), 865-888.

Lochner, L. J., Monge-Naranjo, A., October 2011. The nature of credit constraints and human capital. American Economic Review 101 (6), 2487-2529.

Lochner, L. J., Monge-Naranjo, A., September 2012. Credit constraints in education. Annual Review of Economics 4, 225-256.

Lochner, L. J., Monge-Naranjo, A., January 2015. Student loans and repayment: Theory, evidence and policy. Working Paper 20849, National Bureau of Economic Research.

Marcet, A., Marimon, R., 1992. Communication, commitment, and growth. Journal of Economic Theory 58 (2), 219-249.

Navarro, S., Zhou, J., 2016. Quantifying credit constraints, preferences, and uncertainty in a lifecycle model of schooling choice, under revision, Review of Economic Dynamics. 
Park, Y., 2016. Heterogeneity in parental altruism and optimal higher education subsidies, working paper, Canadian Economic Analysis Department, Bank of Canada.

Zeldes, S. P., April 1989. Consumption and liquidity constraints: An empirical investigation. Journal of Political Economy 97 (2), 305-346. 